\title{
¿On the Influence of Sea Surface Temperature Distributions on the Development of Extratropical Cyclones
}

\author{
HAi BUi ${ }^{\mathrm{a}}$ AND THOMAS SPENGLER ${ }^{\mathrm{a}}$

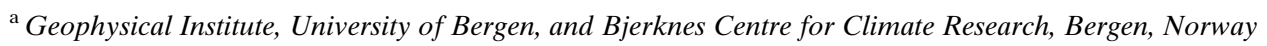

(Manuscript received 7 May 2020, in final form 21 December 2020)

\begin{abstract}
The sea surface temperature (SST) distribution can modulate the development of extratropical cyclones through sensible and latent heat fluxes. However, the direct and indirect effects of these surface fluxes, and thus the SST, are still not well understood. This study tackles this problem using idealized channel simulations of moist baroclinic development under the influence of surface fluxes. The model is initialized with a zonal wind field resembling the midlatitude jet and a different SST distribution for each experiment, where the absolute SST, the SST gradient, and the meridional position of the SST front are varied. The surface latent heat flux associated with the absolute SST plays a key role in enhancing the moist baroclinic development, while the sensible heat fluxes associated with the SST gradient play a minor role that can be detrimental for the development of the cyclone. The additional moisture provided by the latent heat fluxes originates from about $1000 \mathrm{~km}$ ahead of the cyclone a day prior to the time of the most rapid deepening. When the SST in this region is higher than $16^{\circ} \mathrm{C}$, the additional latent heat is conducive for explosive cyclone development. For SSTs above $20^{\circ} \mathrm{C}$, the cyclones feature characteristics of hybrid cyclones with latent heat release close to their core, maintaining their intensity for a longer period due to continuous and extensive moisture supply from the surface. A high absolute SST with a weak SST gradient, however, can lead to a delay of the deepening stage, because of unorganized convection at early stages reducing environmental baroclinicity.
\end{abstract}

KEYWORDS: Atmosphere-ocean interaction; Cyclogenesis/cyclolysis; Extratropical cyclones

\section{Introduction}

Rapidly deepening extratropical cyclones tend to occur over the oceanic western boundary currents that feature strong sea surface temperature (SST) gradients (Sanders and Gyakum 1980; Gyakum et al. 1989; Yoshiike and Kawamura 2009). These SST fronts are the regions of highest air-sea heat exchange in the midlatitudes (Ogawa and Spengler 2019) and collocate with the major storm tracks (Nakamura et al. 2004). While the differential sensible heat fluxes associated with the SST gradient contribute to the low-level baroclinicity (Brayshaw et al. 2008; Nakamura et al. 2008; Taguchi et al. 2009; Papritz and Spengler 2015), the SST gradient itself has little direct effect on the cyclone's intensification (Tsopouridis et al. 2020, $2021 a, b)$. On the other hand, the surface latent heat fluxes on the warmer equatorward side of the SST front can significantly moisten the boundary layer (Small et al. 2014; KuwanoYoshida and Minobe 2017; Small et al. 2019). This additional moisture amplifies the latent heat release in the warm conveyor belt, thereby further intensifying the cyclone (Kuo et al. 1991; Boutle et al. 2010; Hirata et al. 2015; Haualand and Spengler 2020). To further clarify what Haualand and Spengler (2020) coined the direct and indirect effect of surface fluxes on cyclone development associated with the relative importance of

¿ Denotes content that is immediately available upon publication as open access.

Corresponding author: Hai Bui, hai.bui@uib.no surface sensible versus latent heat fluxes, we investigate the development of individual cyclones using different SST distributions.

In general, surface sensible heat fluxes have often been argued to be detrimental to cyclone development (Mansfield 1974; Hoskins and Valdes 1990; Haualand and Spengler 2020). However, consistent with the arguments that the SST front intensifies low-level baroclinicity (Brayshaw et al. 2008; Nakamura et al. 2008; Taguchi et al. 2009), several numerical studies suggest that cyclones become weaker when the SST gradient is smoothed (Jacobs et al. 2008; Sheldon et al. 2017). Nonetheless, varying the SST gradient also leads to changes of absolute SST, where the SST on the equatorward side of the smoothed SST front is lowered (de Vries et al. 2019; Tsopouridis et al. 2020). Thus, it is not the sharpness of the SST front, but the equatorward SST and the associated latent heat flux that can play the dominant role affecting cyclone development (Giordani and Caniaux 2001; Booth et al. 2012; Hirata et al. 2015; de Vries et al. 2019). This assessment was confirmed by numerical studies where the SST was varied by either shifting the SST front to the north or south relative to the developing cyclone (Reed et al. 1993), by adding a uniform SST perturbation (Booth et al. 2012), or by changing the SST gradient through adding a SST perturbation to either side of the SST front (Giordani and Caniaux 2001).

This article is licensed under a Creative Commons Attribution 4.0 license (http://creativecommons.org/ licenses/by/4.0/).

DOI: 10.1175/JAS-D-20-0137.1 
TABLE 1. Physics options for the experiments.

\begin{tabular}{ll}
\hline \multicolumn{1}{c}{ Parameterization scheme } & \multicolumn{1}{c}{ Description } \\
\hline Microphysics & Purdue Lin scheme (Chen and Sun 2002) \\
Cumulus convection & Kain-Fritsch scheme (Kain 2004) \\
Planetary boundary layer physics & Yonsei University scheme (Hong et al. 2006) \\
Surface layer physics & The revised MM5 scheme (Jiménez et al. 2012) \\
Land surface physics & Five-layer thermal diffusion scheme (Dudhia 1996) \\
\hline
\end{tabular}

The different approaches in these studies of varying the SST under a developing cyclone motivated us to design three sets of SST experiments where we vary the absolute SST, the SST gradient, and the position of the SST front.

Regarding the source of the latent heating, Boutle et al. (2010) found that the moisture entering maritime cyclones originates from the cold sector of the preceding cyclone. This remote influence is supported by Kuo et al. (1991), who identified the surface fluxes $24 \mathrm{~h}$ prior to rapid deepening as the main ingredient for cyclone development. Thus, the moisture originates from far ahead of the cyclone before feeding the airstream in the warm sector that converges into the warm conveyor belt where the latent heat is released (Dacre et al. 2019). While most of the latent heat release occurs in the warm conveyor belt, Hirata et al. (2015) argued that a significant fraction of the moisture is fed into the dry cold conveyor belt and released as latent heat in the bent-back front. Thus, while there is agreement about the influence of remote moisture supply, disagreement remains about the exact pathways of the pertinent moisture fluxes.

To disentangle the relative role of surface sensible and latent heat fluxes on the development of extratropical cyclones, we investigate the influence of different SST distributions using an idealized moist baroclinic channel model with reduced physics (Terpstra and Spengler 2015). Similar experiments have already been implemented in numerical models using real data (Reed et al. 1993; Giordani and Caniaux 2001; Booth et al. 2012), though performing systematic sensitivity experiments varying absolute SST, SST gradient, and location of the SST front in an idealized and easy-to-control environment has the advantage that the experiments can be cleanly designed to isolate the direct influence of the SST from the preconditioning and other factors such as the land-sea contrast. While the latter has been found to dominate over the direct effect of the SST front in the Gulf Stream region (Tsopouridis et al. 2021a), it remains important to isolate the influence of a generic SST front and its associated impact through surface sensible and latent heat fluxes on cyclone development.

We separately investigate the influence of surface sensible and latent heat fluxes on cyclone development with a generic SST front. We also examine the energetics of the cyclone development to gain an understanding of the relative role of surface latent and sensible heat fluxes, as well as the pathway of the additional moisture from the sea surface that contributes to the deepening of extratropical cyclones.

\section{Method and experiment design}

We use the Advanced Research Weather Research and Forecasting (WRF) Model (version 3.8.1; Skamarock et al. 2008) configured as a periodic zonal channel with a length of $16000 \mathrm{~km}$ and a meridional width of $6000 \mathrm{~km}$ with symmetric boundary conditions in the meridional direction. The horizontal resolution is $20 \mathrm{~km}$, which is sufficient to simulate a realistic development of extratropical cyclones (e.g., Schemm et al. 2013; Tierney et al. 2018). We choose a relatively high model top of $25 \mathrm{~km}$ to ensure that the jet stream lies well below the Rayleigh damping layer and the rigid lid at the upper boundary. The vertically stretched grid has 61 levels with a higher resolution near the surface (16 levels below $1 \mathrm{~km}$ ) to better resolve surface processes.

The Coriolis parameter is set to $45^{\circ} \mathrm{N}(f=1.028 \times$ $\left.10^{-4} \mathrm{~s}^{-1}\right)$ and the radiation processes are turned off in all simulations. The use of an $f$ plane without radiation

TABLE 2. Options for the prescribed jet stream and the initialization of the basic state and perturbation.

\begin{tabular}{lcl}
\hline \hline Options & Value & \multicolumn{1}{c}{ Description } \\
\hline$U_{0}$ & $50 \mathrm{~m} \mathrm{~s}^{-1}$ & Jet magnitude \\
$Z_{\text {jet }}$ & $8 \mathrm{~km}$ & Altitude of the jet core \\
$L_{y}$ & $1000 \mathrm{~km}$ & Meridional extent of the jet \\
$L_{z}$ & $10 \mathrm{~km}$ & Vertical extent of the jet \\
$p_{0}$ & $1013 \mathrm{hPa}$ & Sea level pressure at the southern boundary \\
$\theta_{0}$ & $295 \mathrm{~K}$ & Surface potential temperature at the southern boundary \\
$Z_{\text {trop }}$ & $10 \mathrm{~km}$ & Tropopause height at the southern boundary \\
$N_{\text {trop }}^{2}$ & $1 \times 10^{-4} \mathrm{~s}^{-2}$ & Static stability in the troposphere \\
$N_{\text {stra }}^{2}$ & $5.6 \times 10^{-4} \mathrm{~s}^{-2}$ & Static stability in the stratosphere \\
$Z_{\text {pert }}$ & $0 \mathrm{~km}$ & Altitude of the initial perturbation \\
$R_{\text {pert }}$ & $500 \mathrm{~km}$ & Radius of the initial perturbation \\
$H_{\text {pert }}$ & $6 \mathrm{~km}$ & Vertical extent of the initial perturbation \\
$\delta p$ & $-2 \mathrm{hPa}$ & Magnitude of the initial perturbation \\
\hline
\end{tabular}



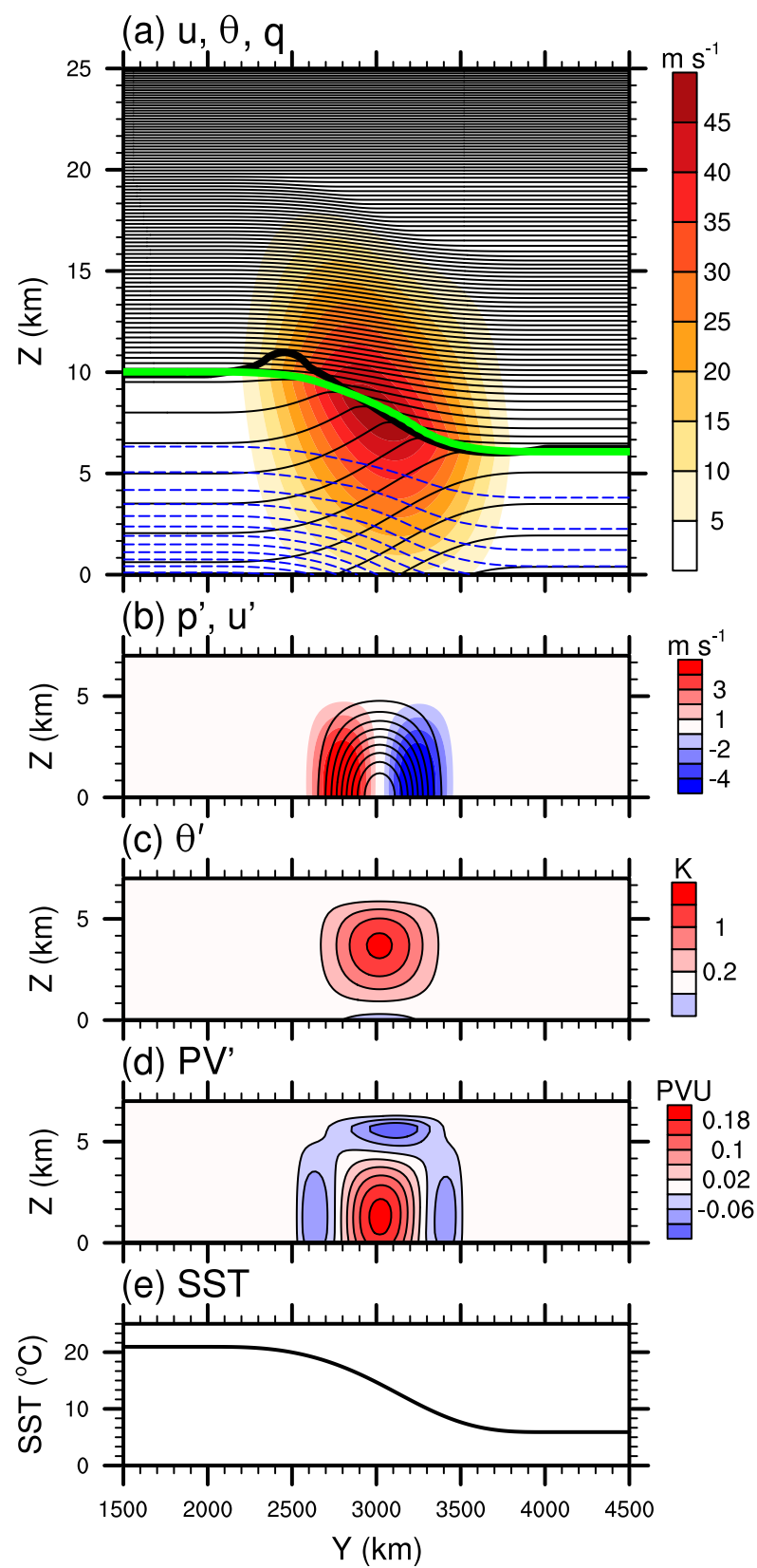

FIG. 1. Initial conditions: (a) zonal wind field (shading, $\mathrm{m} \mathrm{s}^{-1}$ ), potential temperature (thin black contours, from 280 to $765 \mathrm{~K}$ by $5 \mathrm{~K}$ ), water vapor mixing ratio (dashed blue contours, from 1 to $12 \mathrm{~g} \mathrm{~kg}^{-1}$ by $1 \mathrm{~g} \mathrm{~kg}^{-1}$ ), tropopause (thick green line, lapse rate $=2 \mathrm{~K} \mathrm{~km}^{-1}$ ), and the dynamic tropopause [thick black line, 2 PVU surface (1 PVU $=10^{-6} \mathrm{~K} \mathrm{~m}^{2} \mathrm{~kg} \mathrm{~s}^{-1}$ )]; (b) pressure perturbation (contours every $20 \mathrm{~Pa}$ from -180 to $-20 \mathrm{~Pa}$ ) and zonal wind perturbation (shading, $\mathrm{m} \mathrm{s}^{-1}$ ); (c) potential temperature perturbation $(\mathrm{K})$; (d) potential vorticity perturbation (PVU); (e) the sea surface temperature of CTL. The plotted domain is $3000 \mathrm{~km}$, which is half of the original domain.
TABLE 3. Overview of the baseline experiments.

\begin{tabular}{lcc}
\hline \hline Expt & LH flux & SH flux \\
\hline CTL & Yes & Yes \\
NoFx & No & No \\
LHFx & Yes & No \\
SHFx & No & Yes \\
\hline
\end{tabular}

is a common choice for idealized studies and aims to simplify the model physics while retaining the essential processes for the development of extratropical cyclones (e.g., Schemm et al. 2013; Tierney et al. 2018). The zonally uniform sea surface temperature is prescribed at the lower boundary and is not altered in time. The complete list of physical parameterizations is provided in Table 1 .

All experiments are integrated for 5 days with a time step of $40 \mathrm{~s}$. The model output is stored every $3 \mathrm{~h}$ and interpolated to pressure levels every $50 \mathrm{hPa}$ from 100 to $1000 \mathrm{hPa}$. For our analysis, we track the center of the primary cyclone using minimum eddy sea level pressure, which is defined as the sea level pressure minus its zonal mean.

\section{a. Basic-state initialization}

The idealized initial conditions are derived from a prescribed jet stream using the thermal wind equation (Terpstra and Spengler 2015). Compared to methods prescribing a temperature field (e.g., Schemm et al. 2013), this method has the advantage that the zonal wind can be limited in the vertical to reduce the interference with the boundary condition at the model top. However, this method demands a careful choice of background stratification and shape of the jet due to the meridional variation of tropospheric stratification $\left[N^{2}=(\mathrm{g} /\right.$ $\theta)(\partial \theta / \partial z)]$ being proportional to the second derivative of zonal wind with respect to the height $\left(\partial N^{2} / \partial y \propto \partial^{2} u / \partial z^{2}\right)$.

Thus, we chose a jet profile with a constant vertical shear below the tropopause to ensure the tropospheric $N^{2}$ to be constant (see the appendix for details and Table 2 for the parameters used). The jet is moderately strong with a maximum of $50 \mathrm{~m} \mathrm{~s}^{-1}$ at $8 \mathrm{~km}$ altitude in the center of the domain (Fig. 1a). From south to north, the altitude of the tropopause and the surface temperature decrease by about $4 \mathrm{~km}$ and $15 \mathrm{~K}$ across the domain, respectively (Fig. 1a).

The moisture is initialized similarly to Terpstra et al. (2015) by specifying a vertical distribution of relative humidity,

$$
\operatorname{rh}(z)=\mathrm{rh}_{0} \exp \left[-0.5\left(\frac{z}{z_{\mathrm{rh}}}\right)^{n}\right]
$$

where the maximum relative humidity at the surface $\mathrm{rh}_{0}=$ $80 \%$, the scaling height $z_{\text {rh }}=8 \mathrm{~km}$, and the decaying parameter $n=4$. This relative humidity distribution results in a maximum water vapor mixing ratio of about $12 \mathrm{~g} \mathrm{~kg}^{-1}$ near the surface on the southern side of the jet. The mixing ratio decreases northward and with height (Fig. 1a).

\section{b. Initial perturbation}

We define the initial perturbation by introducing a finite pressure perturbation 
TABLE 4. Overview of the SST sensitivity experiments.

\begin{tabular}{lcccc}
\hline \hline \multicolumn{1}{c}{ Expt } & Diff $(\mathrm{K})$ & Scale & Shift $(\mathrm{km})$ & Comment \\
\hline CTL & 0 & 1 & 0 & Control experiment \\
$A-2 \mathrm{~K}, A-4 \mathrm{~K}$ & $-2,-4$ & 1 & 0 & Absolute SST \\
$A+2 \mathrm{~K}, A+4 \mathrm{~K}$ & 2,4 & 1 & 0 & \\
$G / 2, G / 4$ & 0 & $1 / 2,1 / 4$ & 0 & SST gradient \\
$G^{*} 2, G^{*} 4$ & 0 & 2,4 & 0 & SST front position \\
$P-500 \mathrm{~km}, P-1000 \mathrm{~km}$ & 0 & 1 & $-500,-1000$ & \\
$P+500 \mathrm{~km}, P+1000 \mathrm{~km}$ & 0 & 1 & 500,1000 & \\
\hline
\end{tabular}

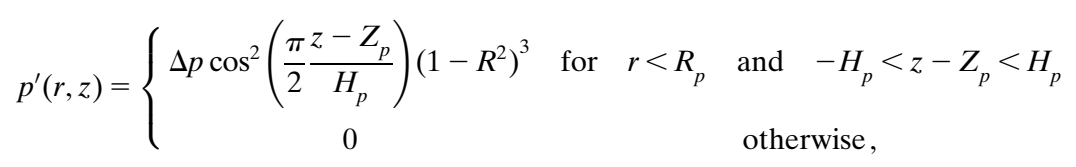

where $\Delta p$ is the perturbation magnitude; $R=r / R_{p}$ is the standardized distance from the perturbation location; $r=\sqrt{x^{2}+y^{2}}$, with $x$ and $y$ being the zonal and meridional coordinates with origin in the center of the cyclone and domain, respectively; $z$ is the height; $Z_{p}$ is the core altitude of the perturbation; and $H_{p}$ is the vertical extend of the perturbation. The radial weighting term $\left(1-R^{2}\right)^{3}$ ensures that the vorticity, which is proportional to the second derivative of pressure with radius, vanishes at the boundary of the perturbation $\left(r=R_{p}\right)$.

After defining the pressure perturbation, we compute the perturbation air density by solving the hydrostatic equation. Finally, the perturbation temperature field and the horizontal wind are derived from the equation of state and the geostrophic equation, respectively. Compared to using a potential vorticity (PV) perturbation to initialize the perturbation (e.g., Schemm et al. 2013), our method does not require a PV inversion procedure and guarantees that the perturbation is both balanced and does not feature a far field.

We define a weak surface-based pressure perturbation (see Table 2 for the parameters used) that results in a horizontal wind perturbation featuring a maximum of about $5 \mathrm{~m} \mathrm{~s}^{-1}$ at half the perturbation radius (Fig. 1b). The derived potential temperature perturbation has a maximum of about $1.5 \mathrm{~K}$ at a height of $4 \mathrm{~km}$ (Fig. 1c). The derived PV perturbation has a maximum of about 0.2 potential vorticity units (PVU; $1 \mathrm{PVU}=10^{-6} \mathrm{~m}^{2} \mathrm{~s}^{-1} \mathrm{~K} \mathrm{~kg}^{-1}$ ) at $1 \mathrm{~km}$ and a negative "shell" around the positive PV perturbation shielding the far field (Fig. 1d).

\section{c. Prescription of SST}

We define a reference sea surface temperature $\operatorname{SST}_{0}(y)$ in the domain $y \in[-\infty,+\infty]$,

$$
\operatorname{SST}_{0}(y)= \begin{cases}T_{s}\left(D_{y}\right) & \text { for } \quad y>D_{y} \\ T_{s}(y) & \text { for }-D_{y} \leq y \leq D_{y} \\ T_{s}\left(-D_{y}\right) & \text { for } \quad y<-D_{y}\end{cases}
$$

where $y$ is the meridional coordinate with the origin in the center of the domain, $D_{y}$ is the meridional half width of the model, and $T_{s}(y)$ is set to the initial meridional distribution of the near-surface atmospheric temperature.

In the control experiment, we set the sea surface temperature to $\mathrm{SST}_{0}$, with highest temperatures of about $21^{\circ} \mathrm{C}$ in the south and lowest temperatures of about $6^{\circ} \mathrm{C}$ in the north (see Fig. 1e). The other experiments feature different absolute SST, SST gradients, and SST front positions using

$$
\operatorname{SST}(y)=\operatorname{SST}_{0}[\alpha(y-\Delta y)]+\Delta \operatorname{SST},
$$

where $\Delta$ SST changes the absolute SST evenly throughout the domain without changing the SST gradient, $\alpha$ defines the magnitude of the SST gradient, and $\Delta y$ sets the location of the SST front. Note that due to the variations in $\alpha, y$ is not limited to $\left[-D_{y},+D_{y}\right]$. Hence, we defined $\operatorname{SST}_{0}(y)$ in a domain with $y \in[-\infty,+\infty]$.

\section{d. Experiment design}

We perform two groups of experiments. First, we run four baseline experiments with $\mathrm{SST}_{0}$, where the surface sensible and latent fluxes are enabled in the control experiment (CTL) and either sensible (LHFx) or latent (SHFx) heat fluxes or both (NoFx) are turned off in the other experiments (see Table 3). These experiments are designed to separate the effects of latent and sensible heat fluxes on cyclone development.

Second, we perform 15 SST sensitivity experiments with different parameters in (4) to examine the influence of different SST distributions on the development of cyclones, where both sensible and latent heat fluxes are always enabled. There are three sets of experiments, where either the absolute SST, the SST gradient, or the location of the SST front position is varied (see Table 4 and Fig. 2). We note that the names of the experiments reflect the SST conditions under the cyclone at the initial time. The absolute SST and SST gradient varies underneath the cyclone 
(a) Absolute SST

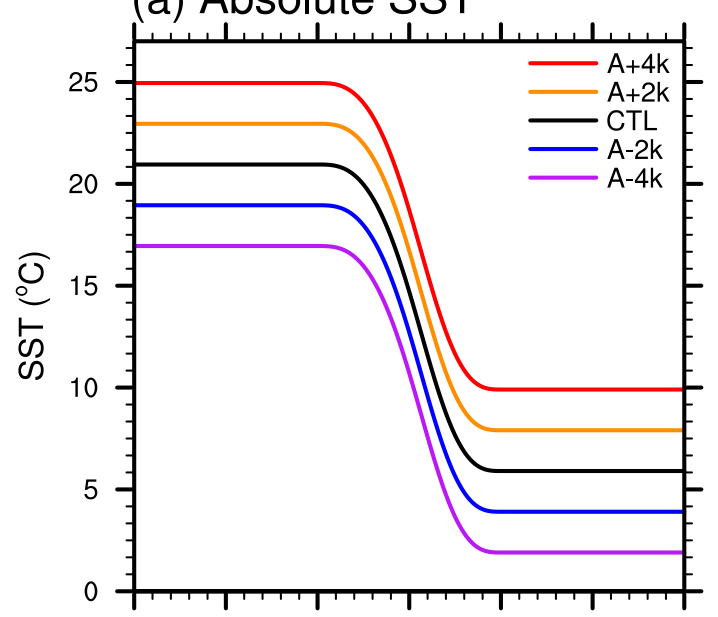

(b) SST gradient

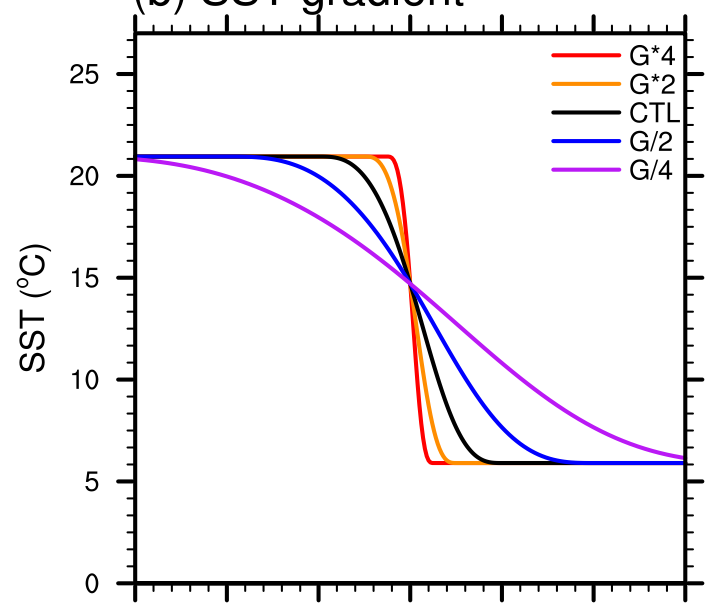

(c) SST front position

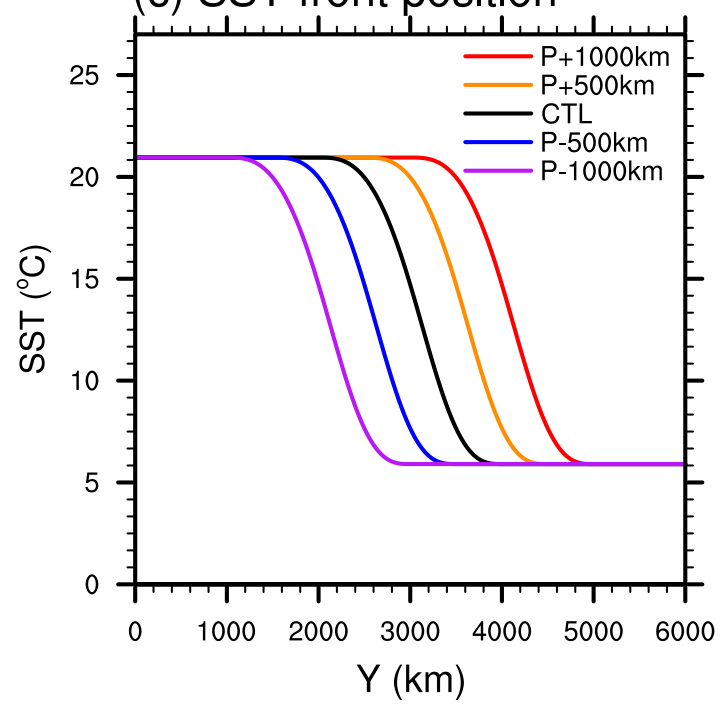

FIG. 2. Meridional profiles of the zonally uniform SST for the three series of sensitivity experiments. with time as the cyclones propagate meridionally during the integration.

\section{e. Energy analysis}

We use the energy framework of Lorenz (1955) to diagnose the cyclone evolution,

$$
\begin{aligned}
& \frac{\partial A_{E}}{\partial t}=C_{A}+G_{E}-C_{E}+R_{A_{E}}, \\
& \frac{\partial K_{E}}{\partial t}=C_{K}+C_{E}+R_{K_{E}},
\end{aligned}
$$

where $A_{E}$ is the eddy available potential energy (EAPE); $K_{E}$ is the eddy kinetic energy (EKE); $C_{A}$ and $G_{E}$ are the baroclinic and diabatic production term, respectively; $C_{E}$ is the conversion from $A_{E}$ to $K_{E} ; C_{K}$ is the barotropic conversion from zonal kinetic energy; and $R_{A_{E}}$ and $R_{K_{E}}$ are residual terms.

As we are interested in the processes within a limited region around the developing cyclone, we define the cycloneaveraged eddy available potential energy $A_{E}$ and eddy kinetic energy $K_{E}$,

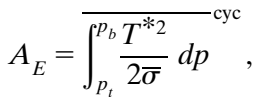

$$
\begin{aligned}
& K_{E}=\frac{1}{g}{\overline{\int_{p_{t}}^{p_{b}} \frac{1}{2}\left(u^{* 2}+v^{* 2}\right) d p}}^{\mathrm{cyc}},
\end{aligned}
$$

where $u$ and $v$ are the horizontal velocity components, $T$ is the temperature, $p$ is the pressure, and $p_{b}=950 \mathrm{hPa}$ and $p_{t}=100 \mathrm{hPa}$ are the bottom and top vertical boundaries for the calculation, respectively. For any arbitrary variable $\phi$, $[\phi]$ denotes the zonal average, $\phi^{*}$ the eddy component, defined as the deviation from the zonal average $(\phi=[\phi]+$ $\left.\phi^{*}\right), \bar{\phi}$ the horizontal average over the entire domain, and $\phi^{\prime}$ the deviation from the domain average. The term $\bar{\sigma}=g\left[\bar{T} / c_{p}-\left(p / R_{d}\right)(\partial \bar{T} / \partial p)\right]$ is proportional to the domainaverage static stability with $g, c_{p}$, and $R_{d}$ being the gravitational acceleration, heat capacity of dry air at constant pressure, and gas constant of dry air, respectively. The superscript $\bar{\phi}^{\text {cyc }}$ denotes that the average is taken within an averaging box around the cyclone.

We choose the size of the averaging box as large as possible so that the influence of the boundaries is minimal. However, the domain cannot be too large either as it would otherwise overlap with the environment of the downstream cyclone. Thus, we choose an averaging box of $2000 \mathrm{~km} \times 2000 \mathrm{~km}$, motivated by the distance between the primary cyclone and the downstream cyclone of about $4000 \mathrm{~km}$.

Due to their importance in assessing the differences in the development, we mainly focus on the baroclinic $\left(C_{A}\right)$ and the diabatic production terms $\left(G_{E}\right)$,

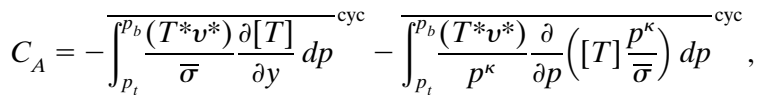


(a)

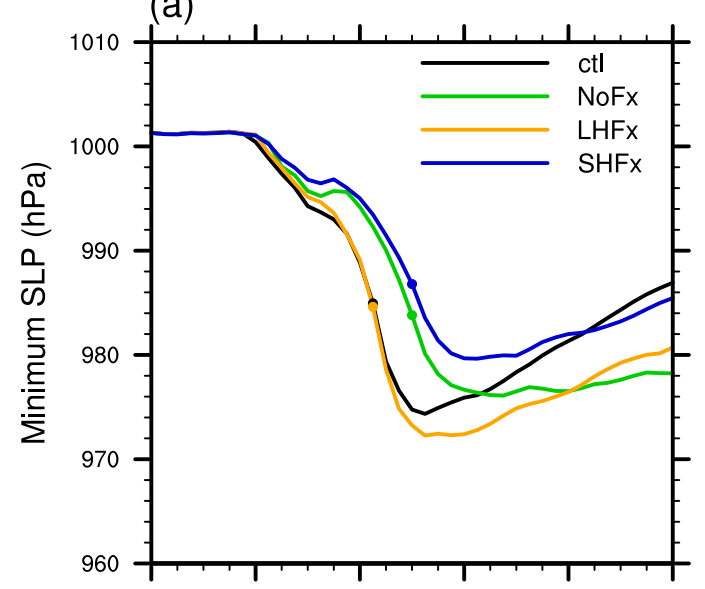

(c)

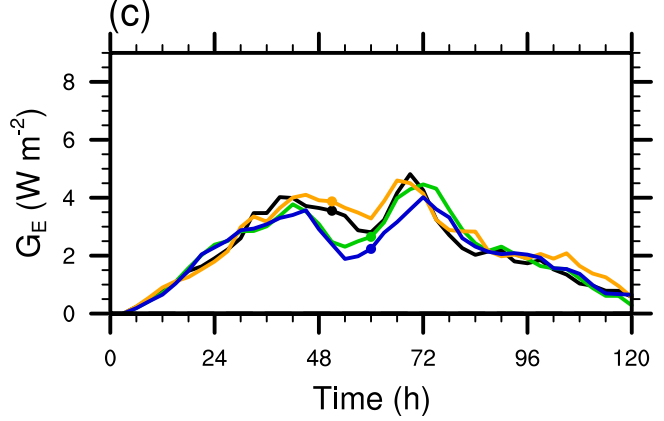

(b)

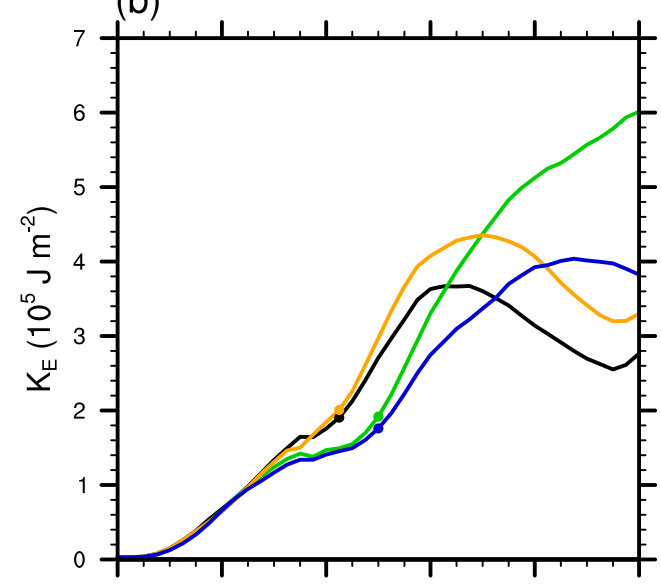

(d)

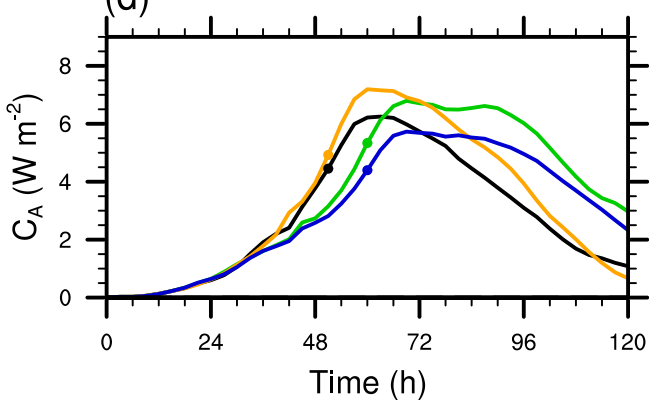

FIG. 3. Time evolution for baseline experiments: (a) minimum sea level pressure (hPa); (b) cyclone-averaged $K_{E}$ $\left(\mathrm{J} \mathrm{m}^{-2}\right)$; (c) cyclone-averaged $G_{E}\left(\mathrm{~W} \mathrm{~m}^{-2}\right)$; (d) cyclone-averaged $C_{A}\left(\mathrm{~W} \mathrm{~m}^{-2}\right)$. The dot on each line indicates the time of fastest deepening rate.

$$
G_{E}=\frac{1}{g}{\overline{\int_{p_{t}}^{p_{b}}} T^{*} Q^{*} \frac{\Gamma_{d}}{\bar{\sigma}} d p}^{c y c}
$$

where $\Gamma_{d}=g / c_{p}$ and $\kappa=R_{d} / C_{p}$. EAPE is converted to EKE via

$$
C_{E}=-\int_{p_{t} p_{b} R_{d}}^{p} T^{*} \omega^{*} d p
$$

The main contribution to $C_{A}$ comes from the first term on the right-hand side of (9), where $T^{*}$ and $v^{*}$ depend on the maturity of the cyclone, and $\partial[T] / \partial y$ reflects the environmental baroclinicity. On the other hand, $G_{E}$ depends on both the maturity of the cyclone via $T^{*}$ and the diabatic eddy heating rate $Q^{*}\left(\right.$ in $\mathrm{J} \mathrm{s}^{-1}$ ), which results from the parameterizations of cumulus, as well as boundary layer and microphysical processes. To achieve a positive $G_{E}$, and thus an enhancing effect on the growth of the cyclone, the diabatic heating (cooling) needs to collocate with warm (cold) regions.

We note that Eqs. (7)-(11) are written in a form of $\int_{p} a^{*} b^{*} d p$, i.e., a horizontal average of vertically integrated eddy flux. This order of integration and averaging is different compared to the expressions in Lorenz (1955), $\int_{p} a^{*} b^{*} d p$. However, both expressions are equivalent when written in discrete form: $\left[1 /\left(N x^{*} N y\right)\right] \sum_{i, j}\left[\sum_{k}\left(a *_{i, j, k} b *_{i, j, k}\right) \Delta p\right]=$ $\sum_{k}\left\{\left[1 /\left(N x^{*} N y\right)\right] \sum_{i, j}\left(a^{*}, i, k, k *_{i, j, k}\right)\right\} \Delta p$. We adopted the first expression, because it allows us to examine the horizontal distribution of the energy conversion terms. For example, the horizontal distribution of $C_{E}$ is $c_{E}=\int_{p_{t}}^{p_{b}}\left(R_{d} / p\right) T^{*} \omega^{*} d p$.

\section{f. Trajectory analysis}

To trace the origin of the air that enters the warm conveyor belt, we perform a trajectory analysis based on the method described by Sprenger et al. (2015). Assuming that an air parcel starts at time $t$ at a position $\mathbf{x}_{t}$ and has a velocity $\mathbf{u}\left(\mathbf{x}_{t}\right)$, we calculate its position at the next time step $t+\Delta t$ through a number of iterative steps:

$$
\mathbf{x}_{t+\Delta t}^{i+1}=\mathbf{x}_{t}+\frac{1}{2}\left[\mathbf{u}\left(\mathbf{x}_{t}\right)+\mathbf{u}\left(\mathbf{x}_{t+\Delta t}^{i}\right)\right] \Delta t, \quad i=0,1, \ldots, N-1,
$$

where $i$ is the number of iterations, $N=5$ is the amount of iteration steps, and $\Delta t$ is the integration time step, where a positive (negative) value of $\Delta t$ implies a forward (backward) integration. For the first step, we perform a simple Euler approach: $\mathbf{x}_{t+\Delta t}^{0}=\mathbf{x}_{t}+\mathbf{u}\left(\mathbf{x}_{t}\right) \Delta t$. To improve the accuracy of the trajectory analysis, we used a temporal model output of $1 \mathrm{~h}$ for CTL and the trajectory analysis time step $\Delta t=120 \mathrm{~s}$. The velocity and diagnostic fields are interpolated in time (linear) and space (vertically linear and horizontally bilinear interpolation) from the native WRF coordinates. 

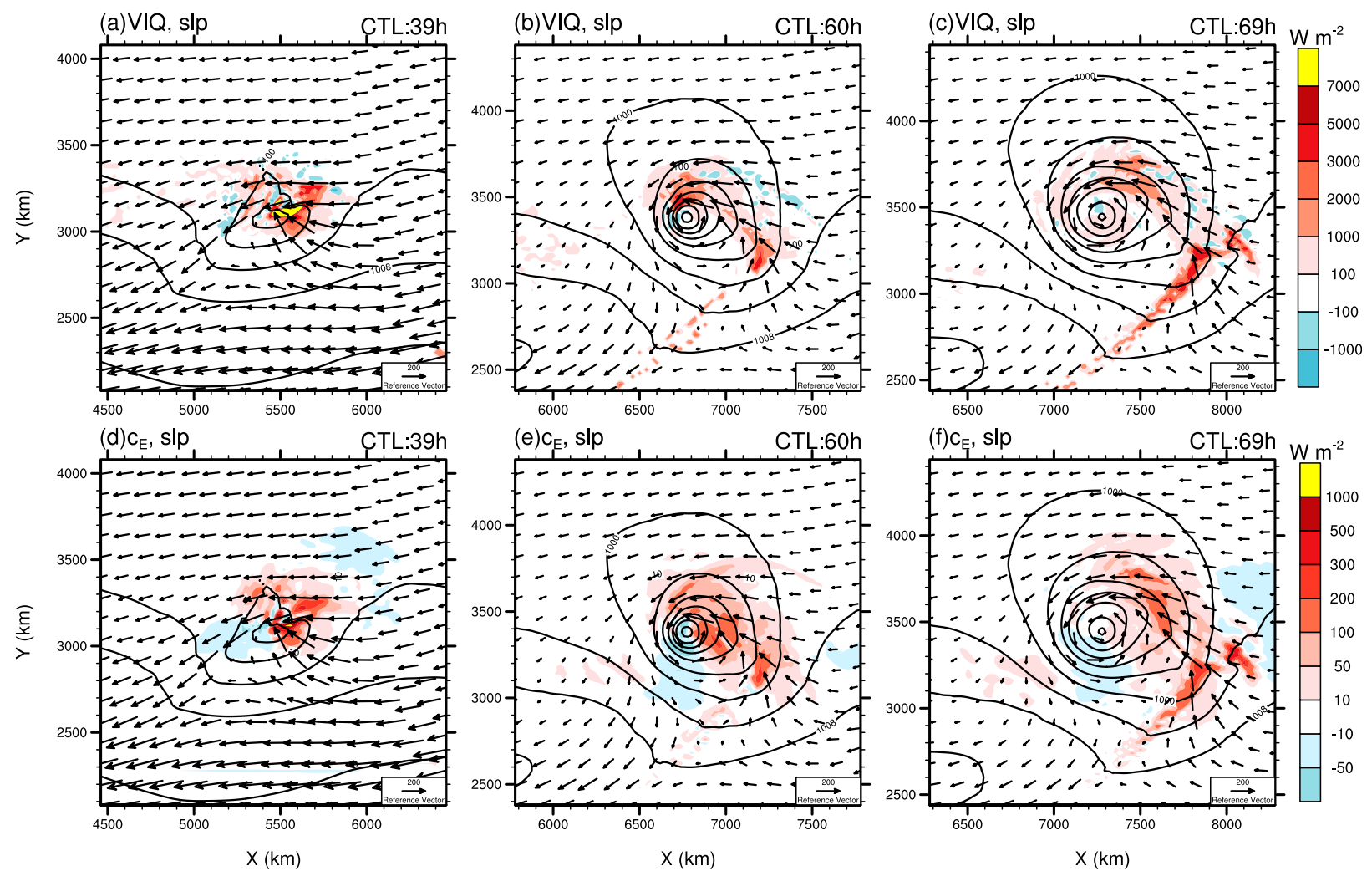

FIG. 4. (a)-(c) Vertically integrated diabatic heating rate (VIQ; shading, $\mathrm{W} \mathrm{m}^{-2}$ ) and (d)-(f) horizontal distribution of the conversion rate $C_{E}$ from EAPE to EKE ( $c_{E}$; shading, $\mathrm{W} \mathrm{m}^{-2}$ ) at (a),(d) 39, (b),(e) 60, and (c),(f) $69 \mathrm{~h}$ of CTL. All panels are overlaid with sea level pressure (black contours, $\mathrm{hPa}$ ) and cyclone-relative low-level $(<1 \mathrm{~km})$ vertically integrated moisture flux vectors. The plotted domain is $2000 \mathrm{~km} \times 2000 \mathrm{~km}$ around the cyclone center.

After obtaining the set of positions of the air parcels, we transform their positions to cyclone-relative coordinates,

$$
\mathbf{r}_{t}=\mathbf{x}_{t}-\mathbf{c}_{t},
$$

where $\mathbf{c}_{t}$ is the center of the cyclone, which is also linearly interpolated in time using the 1-h output data.

To determine the trajectories that go into the warm conveyor belt at the fastest deepening stage at $51 \mathrm{~h}$ for CTL, we first choose the start positions of the air parcels at grid points at the height of $2 \mathrm{~km}$ with vertical velocities greater than $20 \mathrm{~cm} \mathrm{~s}^{-1}$. We then perform a backward integration to $24 \mathrm{~h}$ and a forward integration to $75 \mathrm{~h}$. These combined backward-forward trajectories are considered to belong to the warm conveyor belt if the total ascent is greater than $550 \mathrm{hPa}$, which is slightly smaller than the criteria used in previous studies (Madonna et al. 2014; Sprenger et al. 2015). At $24 \mathrm{~h}$, the warm conveyor belt trajectories start from $x \approx$ $5500 \mathrm{~km}$ and at several different heights within the boundary layer. For a more systematic view on the warm conveyor belt, we then perform a single forward integration from 24 to $75 \mathrm{~h}$, starting at grid points at $x \approx 5500 \mathrm{~km}$ at two different levels of 200 and $400 \mathrm{~m}$. Trajectories at lower levels are not chosen, because the moisture is already nearly saturated with moisture increments being minimal during the integration and trajectories at higher levels tend to not end up in the warm conveyor belt.

\section{Effects of surface fluxes on developing cyclones}

In all baseline experiments (see Table 3 ), the primary cyclone features a $24 \mathrm{~h}$ spinup, followed by a period of intensification of about 1.5 days until reaching maximum intensity, defined by the minimum in central sea level pressure (SLP; Fig. 3a). In general, the cyclone moves eastward and slightly to the south during the first $24 \mathrm{~h}$ before propagating more northward at the beginning of the period of intensification. Compared to NoFx, the cyclone is stronger (weaker) for LHFx (SHFx), with a minimum SLP difference of about $-11 \mathrm{hPa}$ between LHFx and NoFx and about $4 \mathrm{hPa}$ for SHFx and NoFx (Fig. 3a).

Thus, sensible heat fluxes have a small and detrimental effect, while latent heat fluxes significantly aid the deepening of the cyclone. For CTL, the enhancing effect of the latent heat fluxes outweighs the dampening effect of the sensible heat fluxes, such that the minimum SLP is still about $9 \mathrm{hPa}$ deeper compared to NoFx. After 3 days, both latent and sensible heat fluxes yield a dampening effect, as the cyclone for both LHFx and SHFx decays faster compared to NoFx, with the cyclone for CTL decaying the fastest. 
The inclusion of latent heat fluxes strongly enhances the growth of the cyclone's EKE while the inclusion of sensible heat fluxes slightly dampens the growth rate (Fig. 3b). At 2.5 days, $K_{E}$ of LHFx (SHFx) is about $10^{5} \mathrm{~J} \mathrm{~m}^{-2}$ greater $\left(2 \times 10^{4} \mathrm{~J} \mathrm{~m}^{-2}\right.$ smaller $)$ compared to NoFx. The changes in $K_{E}$ can be traced to the diabatic $\left(G_{E}\right)$ and baroclinic $\left(C_{A}\right)$ production of EAPE (Figs. 3c,d). The small dampening effect for SHFx can be explained by the reduction of $G_{E}$ and $C_{A}$, as the sensible heat flux warms (cools) the cold (warm) sector, reducing low-level baroclinicity (Fig. 5). The latent heat flux, on the other hand, provides additional moisture to the lower atmosphere, which is transported into the warm conveyor belt where it enhances $G_{E}$ (Fig. 3c) and leads to a faster increase (decrease) of $K_{E}$ (SLP) (Figs. 3a,b). The pattern of $G_{E}$ features two peaks, one before and one after the stage of the fastest deepening (Fig. 3c). The evolution of $C_{A}$, on the other hand, is quite smooth and has only one peak occurring around maximum intensity (Fig. 3d).

From the energy perspective, the location of the latent heating reflects the input of available potential energy that aids the deepening of the cyclone. Consistently, the vertically integrated heating (Figs. $4 \mathrm{a}-\mathrm{c}$ ) closely resembles the horizontal distribution of $G_{E}$ (not shown). Thus, the first peak of $G_{E}$ for CTL can be associated with the heating near the cyclone center (Fig. 4a). At later stages, the heating region splits into two maxima, one to the north of the cyclone center and another one along the cold front near the occlusion point (Fig. 4b). At the time of the second peak of $G_{E}$, most of the heating occurs near the occlusion point and along the cold front (Fig. 4c).

The horizontal distribution of $C_{E}$ closely resembles that of $G_{E}$ (Figs. $4 \mathrm{~d}-\mathrm{f}$ ). Thus, the increase of $K_{E}$ can be associated with the first peak of $G_{E}$ occurring in an area close to the cyclone center (Fig. 4a). At the time of the second peak of $G_{E}, C_{E}$ also mainly occurs in a larger area distant from the cyclone center (Fig. 4c) and does not contribute significantly to the deepening process (Figs. 3a,b). Thus, the relative position of latent heating with respect to the cyclone center appears to be important in determining how significantly latent heating contributes to the deepening.

\section{Pathway of additional moisture}

The majority of diabatic heating during the first peak in $G_{E}$ occurs in the warm sector of the cyclone (Fig. 4a) and is associated with latent heat release. The moisture yielding this latent heat release in the warm conveyor belt is provided by low-level moisture fluxes originating from the southeast ahead of the cyclone (Fig. 4) and not from the region of the highest surface sensible (red contours) and latent (blue contours) heat fluxes, which reside in the cold sector in the rear of the cyclone (Fig. 5). With only weak latent heat fluxes in the warm sector and the region southeast of the cyclone (Fig. 5a), the moisture uptake is accumulated over a long fetch of about $1000 \mathrm{~km}$ to the east of the cyclone, from where it takes about one day to travel into the
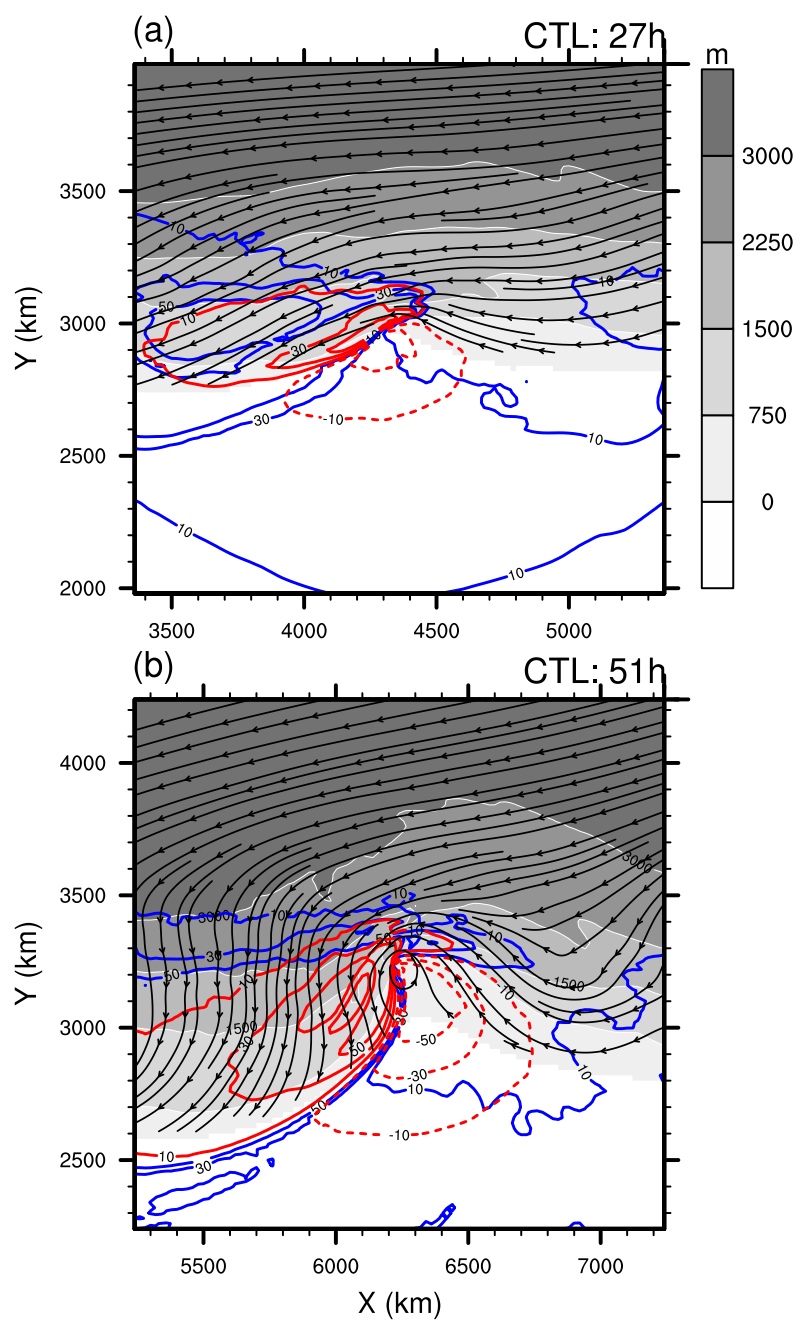

FIG. 5. Altitude of $290 \mathrm{~K}$ isentropic surface at (a) 27 and (b) $51 \mathrm{~h}$ (gray shading with white contours, m), together with streamlines of the cyclone-relative wind along that surface as well as surface latent (blue contours, $\mathrm{W} \mathrm{m}^{-2}$ ) and sensible heat fluxes (red contours, $\mathrm{W} \mathrm{m}^{-2}$ ).

warm conveyor belt. This agrees with the findings of Kuo et al. (1991), who argued that the surface fluxes occurring $24 \mathrm{~h}$ preceding the rapid deepening of the cyclone play an important role in the development of the cyclone.

Analyzing the flow on the $290 \mathrm{~K}$ isentropic surface at the time of fastest deepening (Fig. 5b) as well as $24 \mathrm{~h}$ before (Fig. 5a), it is evident that the airstream experiencing diabatic heating in the warm conveyor belt originated in the lower levels in the warm sector ahead of the cyclone, thereafter gradually gliding upward along the isentropic surfaces into the region of the steepest isentropic slope near the cyclone center where the majority of the heating occurs.

Even though air parcels only stay on isentropic surfaces in the absence of diabatic heating, the forward trajectory analysis of the warm conveyor belt (Fig. 6a) confirms the assessment that the feeding airstream into the warm 
(a) SIp, $\theta_{850}$

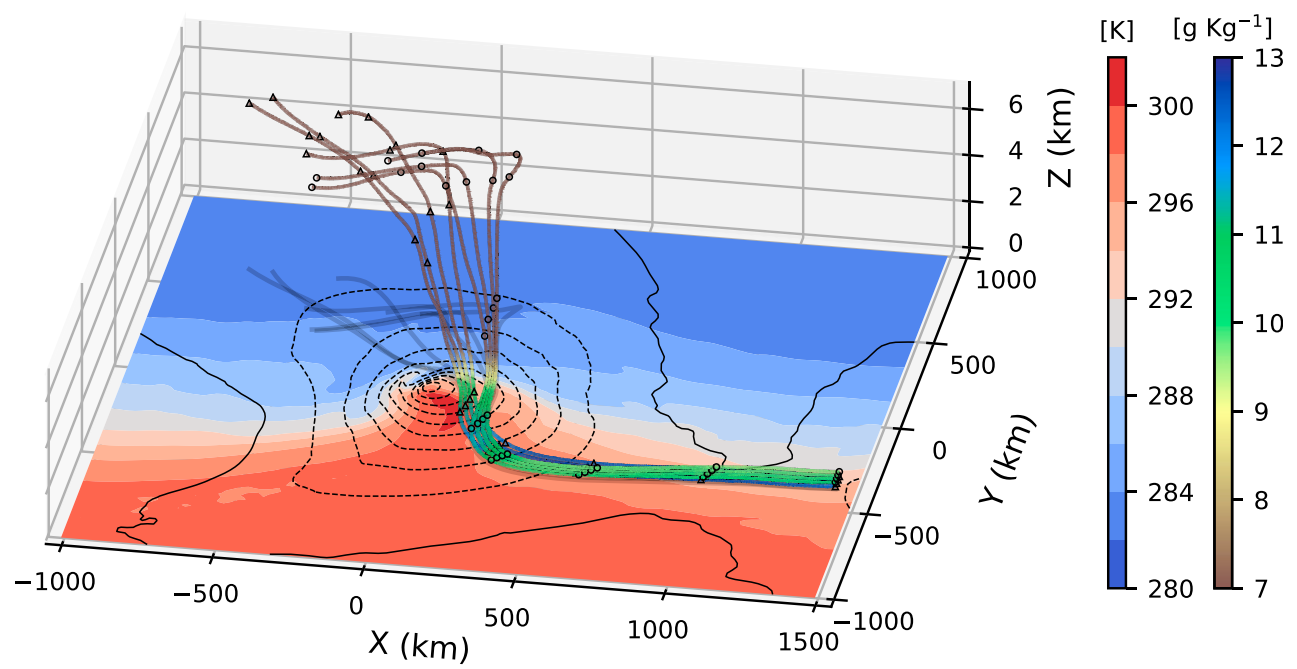

(b) LHF, Qv

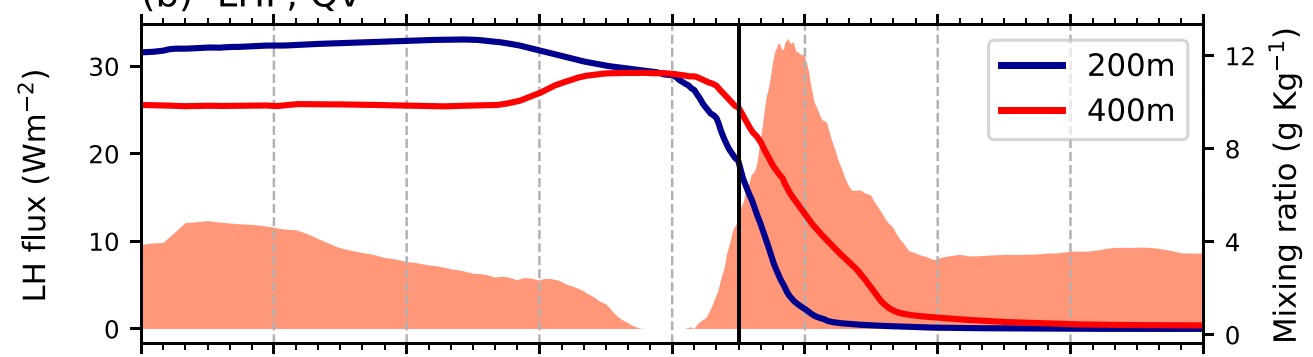

(c) SHF, $\theta$

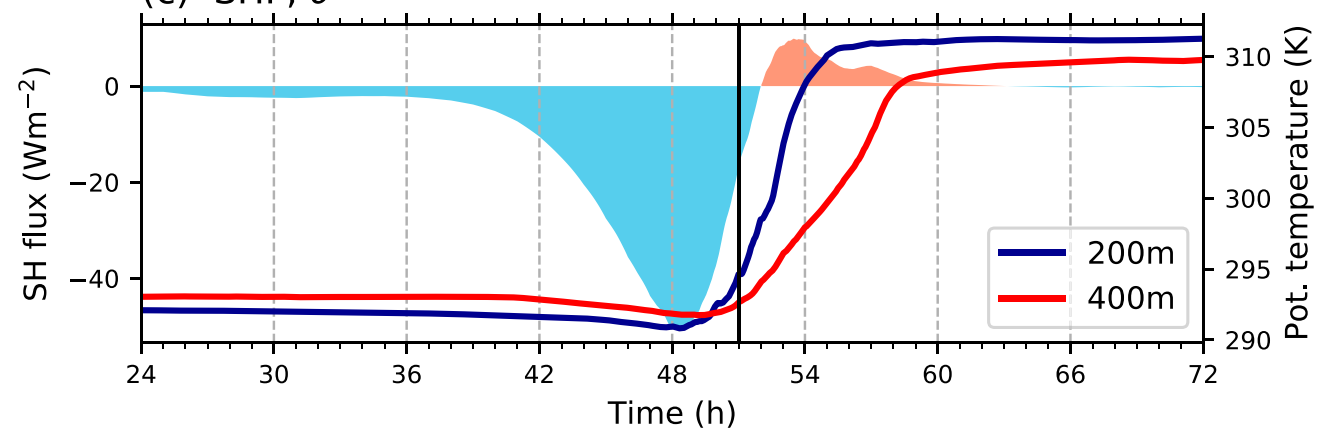

FIG. 6. (a) Selected cyclone-relative forward trajectories from 24 to $75 \mathrm{~h}$ associated with the warm conveyor belt. The trajectories are colored with their water vapor mixing ratios $\left(\mathrm{g} \mathrm{kg}^{-1}\right)$ and marked every $6 \mathrm{~h}$ with circles when originating from $400 \mathrm{~m}$ and with triangles when originating from $200 \mathrm{~m}$. The $850 \mathrm{hPa}$ potential temperature $(\mathrm{K}$, shaded) and sea level pressure anomaly (contours every $2 \mathrm{hPa}$; negative contours are dashed; the innermost contour is $-18 \mathrm{hPa}$ ) at $51 \mathrm{~h}$ are overlaid at $z=0 \mathrm{~m}$. (b) Average water vapor mixing ratio of trajectories with origin at $200 \mathrm{~m}$ (dark blue line) and $400 \mathrm{~m}$ (red line) and averaged latent heat flux underneath (shading). (c) Average potential temperature of trajectories with origin at $200 \mathrm{~m}$ (dark blue line) and $400 \mathrm{~m}$ (red line) and averaged sensible heat flux beneath (shading). The solid vertical line in (b) and (c) indicates the time for the snapshot of potential temperature and sea level pressure in (a).

conveyor belt originates ahead of the cyclone center. In a cyclone-relative perspective, the lower airstream (originating at $200 \mathrm{~m}$ ) moves westward and then northwestward, while the upper airstream (originating at $400 \mathrm{~m}$ ) moves in a larger curvature from westward to northward, before both ascend into the warm conveyor belt. The locations of ascent of the lower trajectories are closer to the cyclone center, which implies a more important role in the deepening process.

The water vapor mixing ratio of the lower airstream increases from 24 until $40 \mathrm{~h}$, which can be associated with the upward latent heat flux underneath (Fig. 6b). From 40 until 

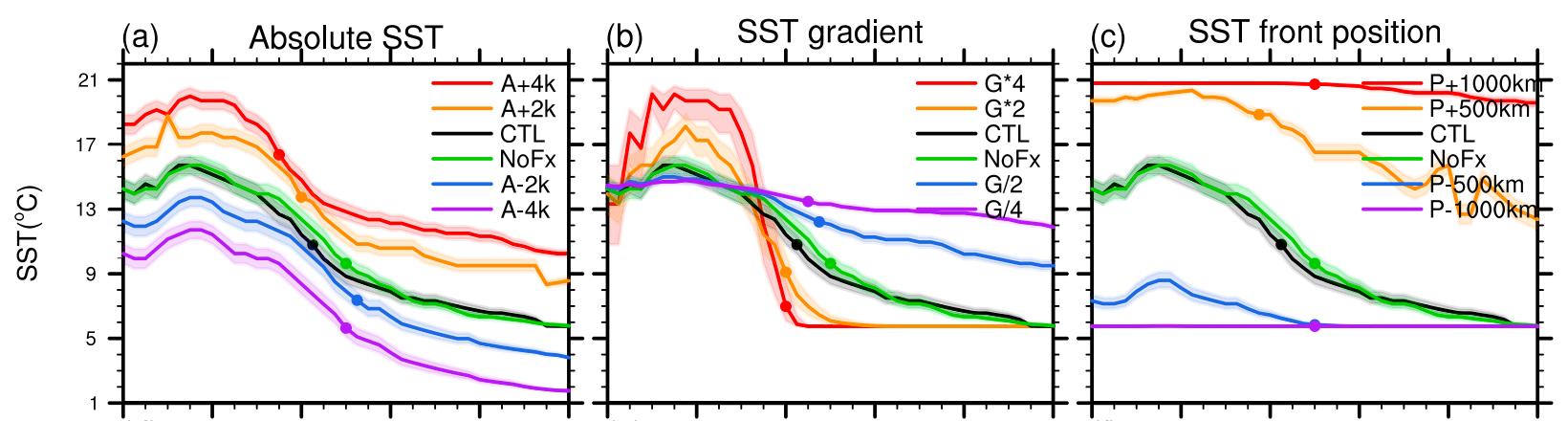

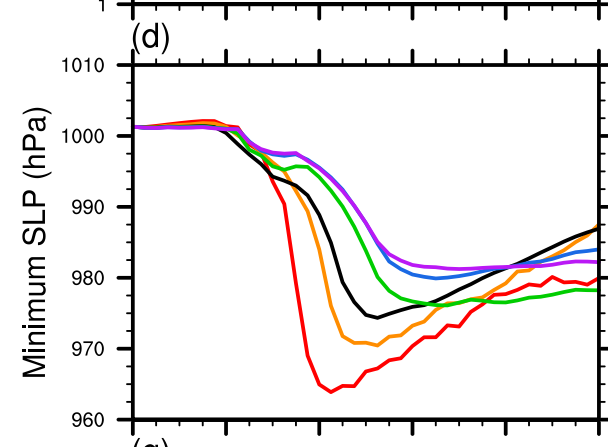

(g)

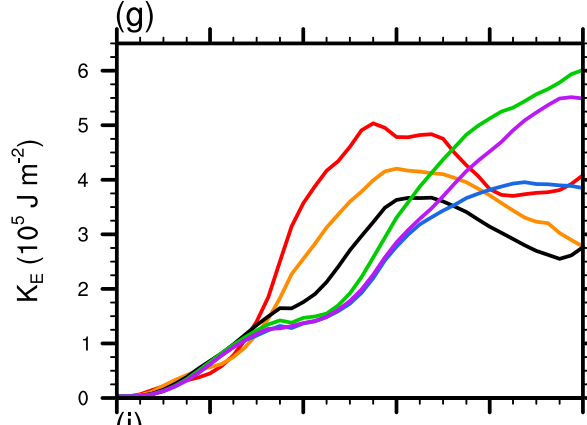

(e)

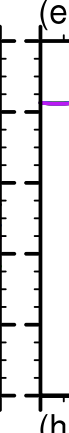

(h)
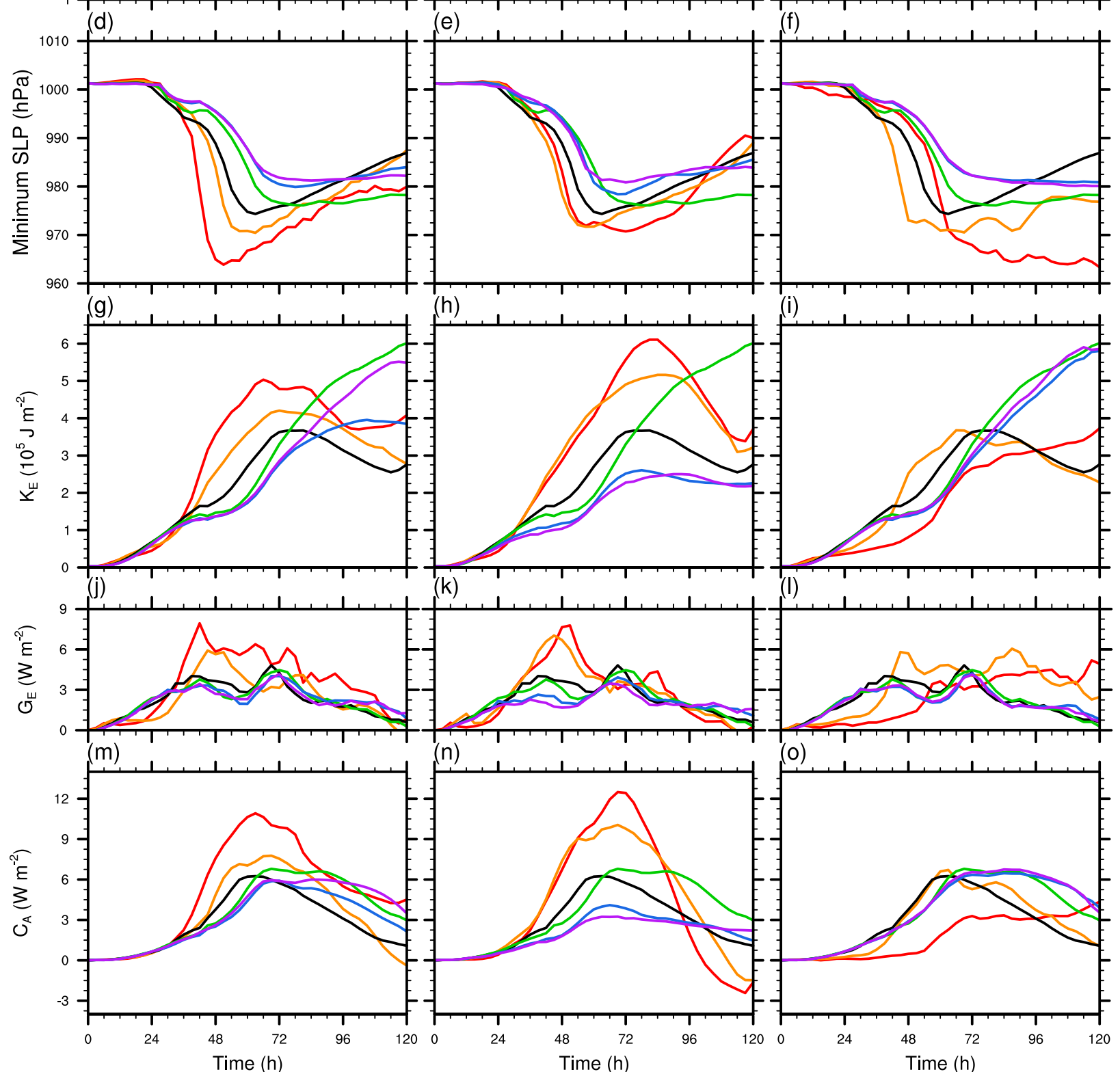

(n)

(0)

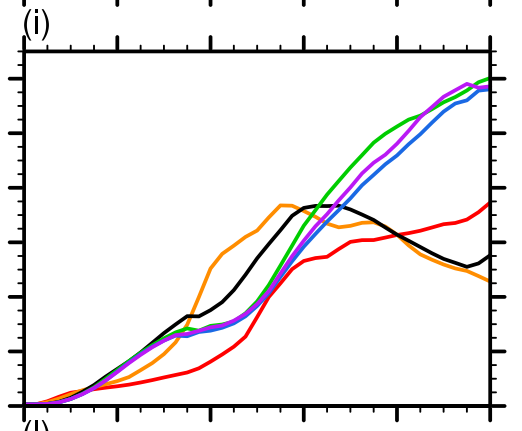

(I)
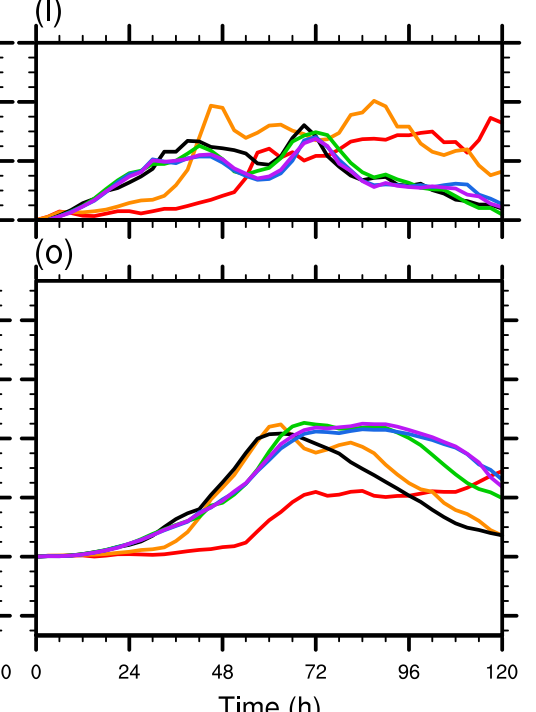

FIG. 7. Time evolution of (a)-(c) SST underneath the cyclone, where the semitransparent shades indicate the SST difference over four grid points around the cyclone's core, representing the magnitude of the SST gradient. The dot on each line indicates the occurrence of the fastest deepening. (d)-(f) Sea level pressure at the cyclone core; (g)-(i) averaged kinetic energy $K_{E}$; (j)-(l) averaged diabatic production term $G_{E} ;(\mathrm{m})-(\mathrm{o})$ averaged baroclinic production term $C_{A}$. (left) Absolute SST experiments, (center) SST gradient experiments, and (right) SST front position experiments. The averaged terms in (g)-(o) are calculated over an area $2000 \mathrm{~km} \times 2000 \mathrm{~km}$ around the cyclone. 
$45 \mathrm{~h}$, the mixing ratio in the lower airstream decreases concomitantly with an increase of mixing ratio in the upper layer. The latter implies an exchange of moisture between the layers due to vertical mixing. After $48 \mathrm{~h}$, both airstreams feature a significant reduction in mixing ratio, which is associated with condensation. The condensation is also clearly visible in the dramatic and proportional increase of potential temperature (Fig. 6c).

The potential temperature of both airstreams decreases slightly from $42 \mathrm{~h}$ until they ascend around $49 \mathrm{~h}$, which is associated with the downward sensible heat flux (Fig. 6c). This cooling is also responsible for the dampening effect on cyclone development associated with the sensible heat flux. We notice that the lower airstream has a lower initial potential temperature, but ascends faster and gains a higher potential temperature compared to the upper airstream. This is consistent with the lower airstream featuring a higher overall loss of mixing ratio (Fig. 6b), which implies a higher release of latent heat and warming (Fig. 6c).

The pathway of the "beneficial moisture" agrees to some extent with Hirata et al. (2015), but due to the northerly and easterly wind they attribute the low-level airflow into the region of diabatic heating to originate from the cold conveyor belt. This attribution is most likely misleading, as the airflow into the heating relevant to the energetics of the cyclone in the warm sector is slightly from the south, which is also evident in their Figs. 9 and 10. Thus, instead of focusing on the cold conveyor belt, the airstream feeding the warm conveyor belt should be considered, which usually does not include air masses that originated from the cold conveyor belt.

\section{SST sensitivity experiments}

\section{a. Relative role of absolute SST and the SST gradient}

Similar to the baseline experiments, the cyclones move eastward and slightly to the south during the first $24 \mathrm{~h}$ before they propagate more northward at the beginning of the deepening phase. Thus, the absolute SST under the cyclone first increases and thereafter decreases, though the rapidity of this change depends on the strength of the SST gradient (Figs. $7 \mathrm{a}-\mathrm{c}$ ). As the differences in the latent heat flux are largely determined by the underlying SST, we categorize the experiments into groups of high SST (orange and red lines in Fig. 7) and low SST (blue and purple lines in Fig. 7), depending on if the maximum absolute SST underneath the cyclone exceeds that of the CTL experiment $\left(16^{\circ} \mathrm{C}\right)$ or not.

Consistent with the results of the baseline experiments, the evolution of SLP and $K_{E}$ can be mainly attributed to the moisture influx determined by the accumulated latent heat flux that is associated with the absolute SST through the Clausius-Clapeyron relation. This is evident in the strong relationship between absolute SST underneath the cyclone $24 \mathrm{~h}$ prior to the fastest deepening and the subsequent intensification of the cyclone (cf. Figs. 7a-i). Hence, high SST cyclones become more intense and deepen faster

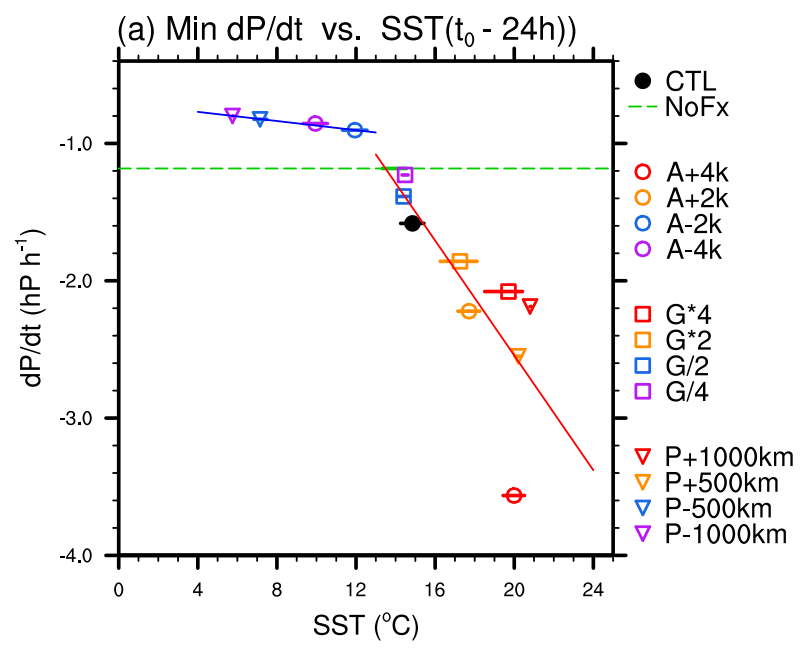

FIG. 8. Scatterplot of the maximum deepening rate $\left(\mathrm{hPa} \mathrm{h}^{-1}\right)$ against the SST (symbols) underneath the cyclone's core $24 \mathrm{~h}$ prior to the fastest deepening. The short solid lines indicate the SST differences $80 \mathrm{~km}$ across the cyclone core, indicating the strength of the SST gradient. The blue and red solid lines are the linear regressions for cases that deepen slower or faster than the NoFx experiment.

than low SST cyclones (Figs. 7d-i), with all high SST cyclones being explosive, meaning that the central SLP drops at least $24 \mathrm{hPa}$ in $24 \mathrm{~h}$ (Sanders and Gyakum 1980).

The minimum SLP in the low SST experiments is about 6-10 hPa higher compared to CTL, while the minimum SLP in the high SST experiments is about $4-12 \mathrm{hPa}$ lower compared to CTL (Figs. 7d-f). After the cyclones matured around day 2 to 3 , the intensity of the low SST cyclones remains mostly unchanged, while the high SST cyclones, except for $P+1000 \mathrm{~km}$, decay with continuously increasing SLP (Figs. 7d-f).

The $K_{E}$ evolution is similar to the evolution of the SLP, with the high SST cyclones growing faster and decaying after around day 3 (Figs. $7 \mathrm{~g}-\mathrm{i}$ ), except for $P+1000 \mathrm{~km}$, where $K_{E}$ is damped about 2 days initially but continues to increase until the end of the integration. $K_{E}$ of the low SST cyclones, on the other hand, maintains its magnitude or even continues to grow until the end of the integration (Figs. $7 \mathrm{~g}-\mathrm{i}$ ).

The evolution of $G_{E}$ for the low SST cyclones is similar to that of CTL, which has two peaks at around day 1.5 and day 3 (cf. Fig. 3c with Figs. $7 g-i$ ). On the other hand, the first peak in $G_{E}$ for high SST cyclones is about 2 times greater than that of low SST cyclones in the absolute SST and $S S T$ gradient experiments. For $P+1000 \mathrm{~km}$, the first peak of $G_{E}$ is about half a day delayed compared to other high SST cases, but also marks the period when the fastest deepening occurs.

In addition to the absolute SST, the SST gradient can also play a role in the growth of $K_{E}$, with the fastest growth occurring in the experiment with the strongest SST gradient $(\mathrm{G} * 4)$. The high $C_{A}$ suggests that the SST gradient can enhance the baroclinicity that is then converted to $K_{E}$. 

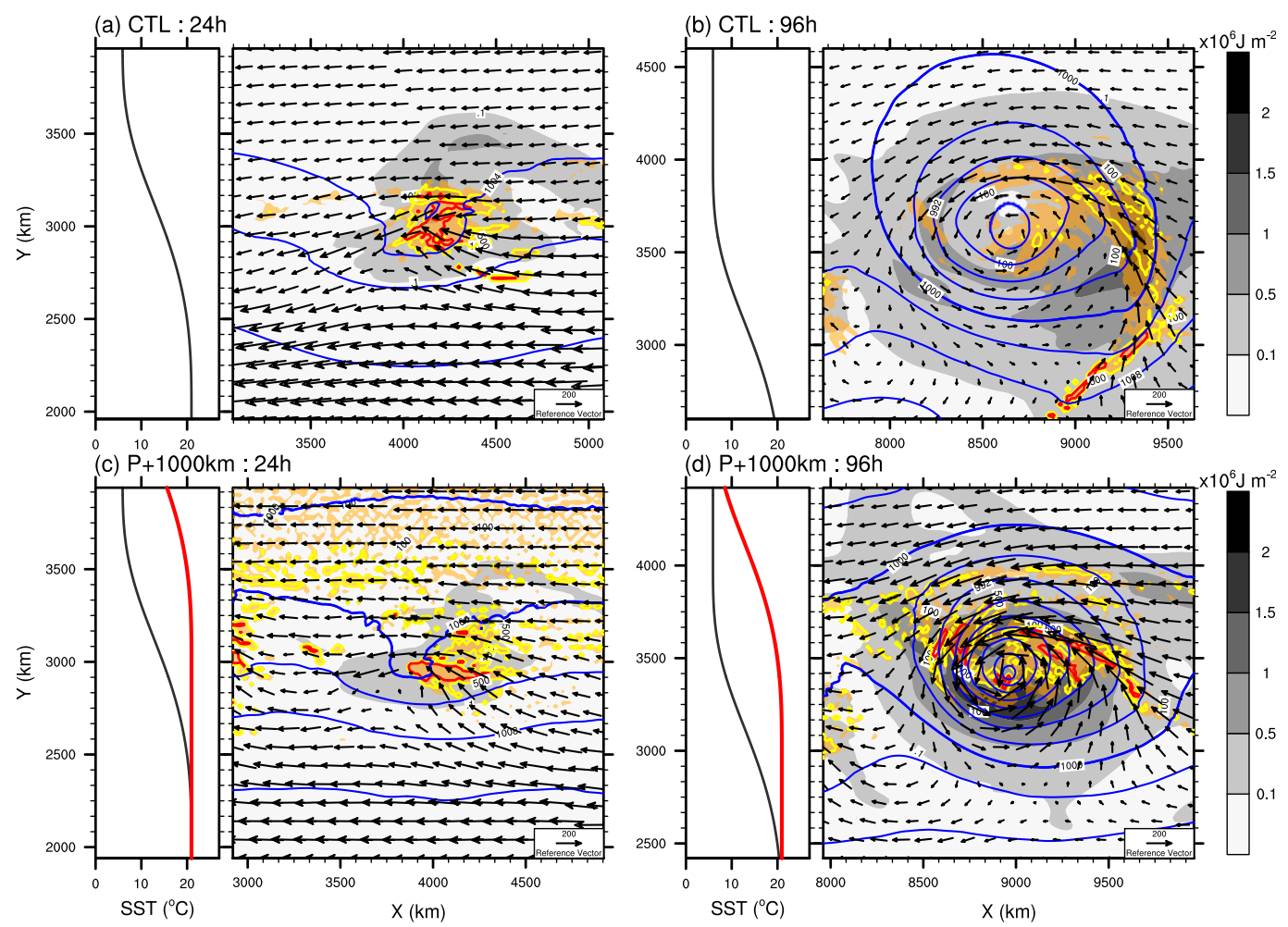

FIG. 9. Sea surface temperature (black lines for CTL and red lines for $P+1000 \mathrm{~km}$ ) and vertically integrated $K_{E}$ (gray shading, $10^{6} \mathrm{~J} \mathrm{~m}^{-2}$ ), sea level pressure (blue contours), and vertically integrated diabatic heating rate (orange shading marks the regions $\geq 100 \mathrm{~J} \mathrm{~m}^{-2} \mathrm{~s}^{-1}$; yellow and red contours are 500 and $2500 \mathrm{~J} \mathrm{~m}^{-2} \mathrm{~s}^{-1}$, respectively) for (a),(b) CTL and (c),(d) $P+1000 \mathrm{~km}$ at (a),(c) 24 and (b),(d) $96 \mathrm{~h}$.

However, $C_{A}$ peaks after the cyclone reaches its deepest SLP and the growth of $K_{E}$ at this point mainly occurs in the outer region of the cyclone (Fig. 4f). This suggests that $C_{A}$ associated with the SST gradient has only a minor contribution to the deepening compared to the role of $G_{E}$ due to the latent heat release associated with the absolute SST.

There is a strong relationship between the deepening rate and the absolute SST that the cyclone encounters $24 \mathrm{~h}$ before $\left(\mathrm{SST}_{t_{0}-24 \mathrm{~h}}\right.$, Fig. 8). Cyclones in experiments with $\mathrm{SST}_{t_{0}-24 \mathrm{~h}}$ below $13^{\circ}$ deepen less rapidly than the cyclone in NoFx. Thus, overall surface fluxes have a relatively small dampening effect in the presence of lower SSTs, where the dampening is mainly associated with the surface sensible heat flux. On the other hand, cyclones in experiments with $\mathrm{SST}_{t_{0}-24 \mathrm{~h}}$ above $13^{\circ} \mathrm{C}$ deepen faster than the cyclone in NoFx. This is due to the enhanced latent heat flux contributing to enhanced diabatic heating in the cyclone that helps to overcompensate for the dampening effect of the sensible heat flux. Thus, the beneficial effect of the latent heat fluxes to the cyclone intensification is much greater than the detrimental effect due to the sensible heat flux. The latter fact is also evident in a much steeper slope of the regression line for the cyclones with $\mathrm{SST}_{t_{0}-24 \mathrm{~h}}$ above $13^{\circ} \mathrm{C}$.

\section{b. Explanation for the deviating behavior in $P+1000 \mathrm{~km}$}

Experiment $P+1000 \mathrm{~km}$ features some intriguing behavior compared to the other high SST experiments, where the SLP deepens for the first $24 \mathrm{~h}$ while $K_{E}$ does not increase significantly. The reduced $K_{E}$ at the beginning is most likely associated with the warm ocean and a weak SST gradient. Comparing $P+1000 \mathrm{~km}$ to CTL at $24 \mathrm{~h}$, there is a large region of scattered heating north of the cyclone triggered by the higher absolute SST (orange shading, Figs. 9a,c). This heating warms the cold sector and thus hampers $C_{A}$. Furthermore, the widespread heating also contributes to a decrease in large-scale SLP, where the $1000 \mathrm{hPa}$ contour is displaced much further south and the initial decrease in SLP (Fig. 7f) is thus not solely associated with the development of the cyclone.

At $96 \mathrm{~h}$, the $P+1000 \mathrm{~km}$ cyclone is still very intense compared to CTL in terms of sea level pressure (Fig. 7f) and eddy kinetic energy (Figs. 9b,d). However, due to its smaller size, $K_{E}$ is more concentrated for $P+1000 \mathrm{~km}$, while yielding a comparable cyclone-averaged $K_{E}$ to CTL (Fig. 7i). During the last 2 days of the integration, the cyclone does not decay, which can be attributed to the higher heating rates near the cyclone center due to the higher absolute SST. This cyclone features characteristics of a "hybrid cyclone" (Yanase and Niino 2019), which has a smaller-scale tropical-cyclone-like convective core.

The effects of the SST on the zonal mean baroclinicity at $24 \mathrm{~h}$ is clearly illustrated in Fig. 10. Over the higher SST, the troposphere is up over $4 \mathrm{~K}$ warmer at $24 \mathrm{~h}$ (red contours for $P+1000 \mathrm{~km}$, Fig. 10a), and most of the heating originates from 


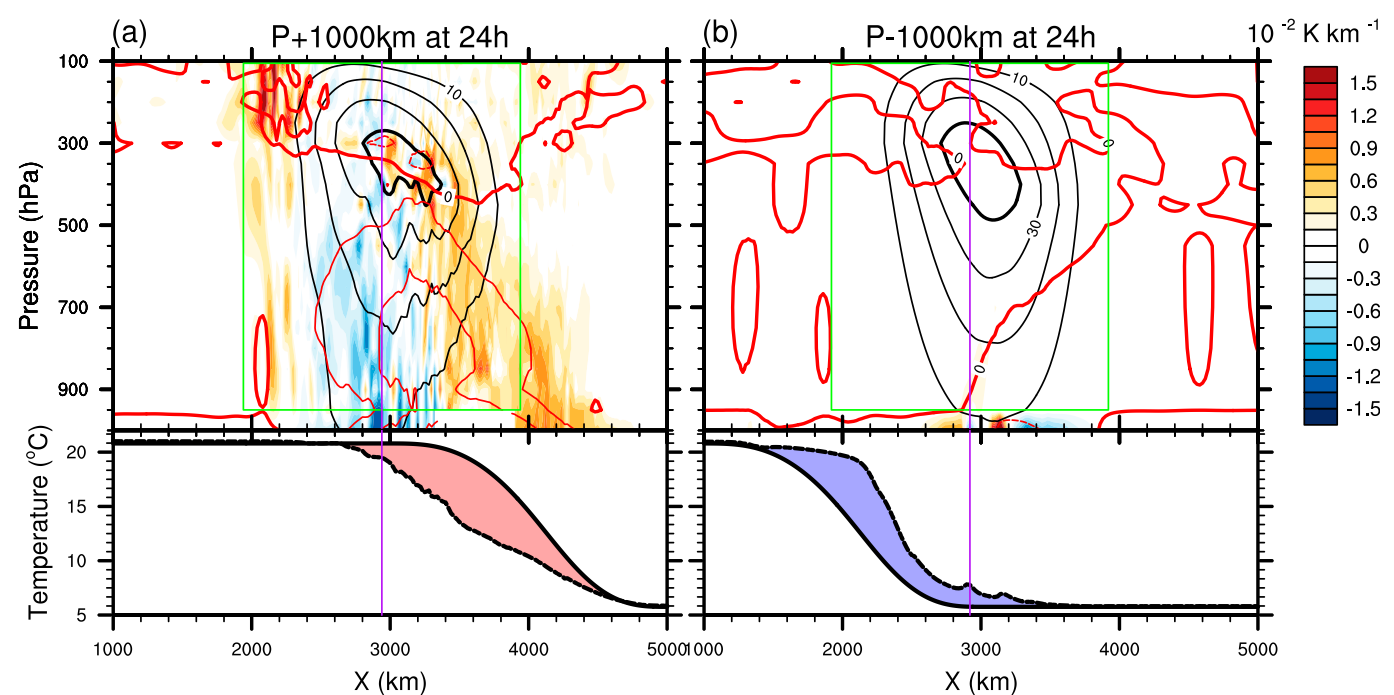

FIG. 10. (top) Meridional cross section $(y-z)$ at $24 \mathrm{~h}$ of zonal mean wind (black contours every $10 \mathrm{~m} \mathrm{~s}^{-1} ; 40 \mathrm{~m} \mathrm{~s}^{-1}$ line is thickened), zonal mean temperature change since initial time (red contours every $2 \mathrm{~K} ; 0 \mathrm{~K}$ line is thickened; negative contours are dashed), and change of zonal mean absolute meridional temperature gradient since the initial time $\left[\mathrm{K}(100 \mathrm{~km})^{-1}\right.$, shaded]. (bottom) SST $\left({ }^{\circ} \mathrm{C}\right.$, solid line) and near-surface air temperature $\left({ }^{\circ} \mathrm{C}\right.$, dashed). The red (blue) shading between the two lines means that the SST is higher (lower) than the near-surface air. Plots are for the (left) $P+1000 \mathrm{~km}$ and (right) $P-1000 \mathrm{~km}$ experiments.

the convective cumulus parameterization scheme (not shown). The result of this heating is a dipole structure in large-scale baroclinicity with the zonal mean temperature gradient being reduced in a region of about $1000 \mathrm{~km}$ to the south of $y=$ $3200 \mathrm{~km}$ and increased at about the same width to the north. The cyclone center is nearly in the middle of the region with reduced baroclinicity. Thus, the deepening rate is weakened initially and the development is delayed compared to $P-$ $1000 \mathrm{~km}$, where the SST only affects a thin layer within the boundary layer (Fig. 10b).

The convective activity over the higher SST also deforms the structure of the zonal mean zonal wind and weakens the jet. This might be partly responsible for a reduced value of average eddy kinetic energy $K_{E}$ of the $P+1000 \mathrm{~km}$ cyclone at later phases. After $24 \mathrm{~h}$, the cyclone starts to move northward, away from the dampening region into the region of enhanced zonal baroclinicity, which also aids the cyclone to deepen faster and to maintain its intensity.

\section{Concluding remarks}

We performed idealized simulations to examine the influence of the SST distribution on the development of extratropical cyclones. In our baseline experiments we find that surface sensible heat fluxes have a small dampening effect on cyclone development while latent heat fluxes play a crucial role in providing additional moisture that enhances diabatic heating in the warm conveyor belt. This is consistent with the direct and indirect effects of surface fluxes coined by Haualand and Spengler (2020), who identified a detrimental direct contribution through sensible heat fluxes and an indirect beneficial contribution through latent heat fluxes providing additional moisture conducive to diabatic cyclone intensification.

In contrast to the arguments by Hirata et al. (2015), the additional moisture does not originate from the cold sector, where the latent heat fluxes are highest. Instead, the feeding airstream gradually takes up moisture from as far as $1000 \mathrm{~km}$ ahead of the cyclone, taking around $24 \mathrm{~h}$ before reaching the warm conveyor belt (Fig. 11). Moreover, it appears that the cyclones deepen more rapidly if the heating region is closer to the cyclone center.

We also conducted a series of sensitivity experiments, where we changed the absolute SST, the SST gradient, and the meridional position of the SST front. The results confirm that the key factor for the deepening of the cyclone is the absolute SST ahead of the cyclone during the $24 \mathrm{~h}$ prior to maximum intensification. This high absolute SST increases the surface latent heat fluxes that contribute to stronger diabatic heating near the cyclone's core. In our experiments, all cyclones with high absolute SST $\left(>16^{\circ} \mathrm{C}\right)$ underneath the cyclone $24 \mathrm{~h}$ prior to the deepening stage have an explosive development.

The SST gradient affects the deepening rate of cyclones in two ways. First, by changing the underlying absolute SST as the cyclone crosses the SST gradient. Second, by modifying the baroclinicity that influences the development of the cyclone. The latter plays only a secondary role, because a cyclone over high absolute SST and a weak SST gradient can still develop explosively after an initial damping phase. In one of our experiments $(P+1000 \mathrm{~km})$, where the underlying absolute SST remains high $\left(\mathrm{SST} \approx 20^{\circ} \mathrm{C}\right)$ until the end of the integration, the cyclone shows characteristics of a hybrid cyclone (Yanase and Niino 2019) that features a smaller size and is maintained mainly by latent heat release near its core. 


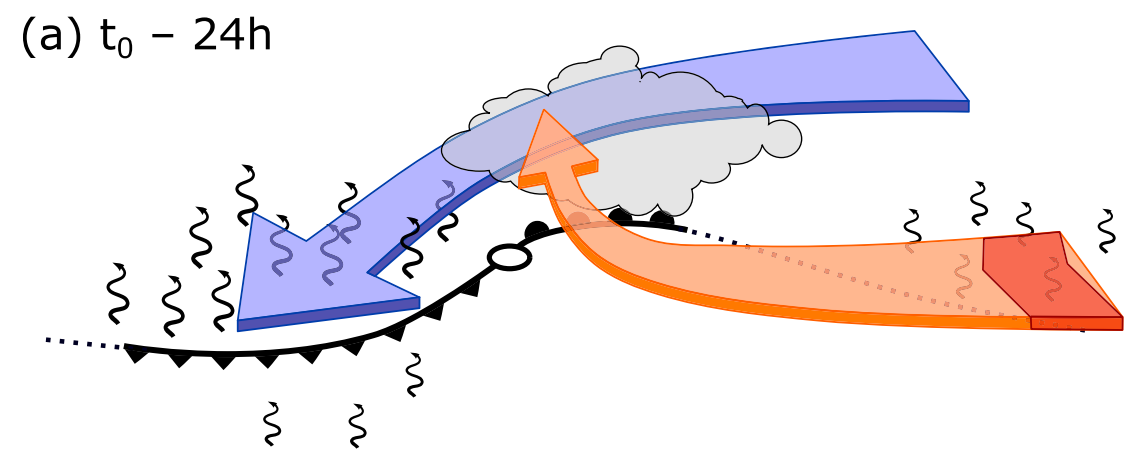

(b) $t_{0}$

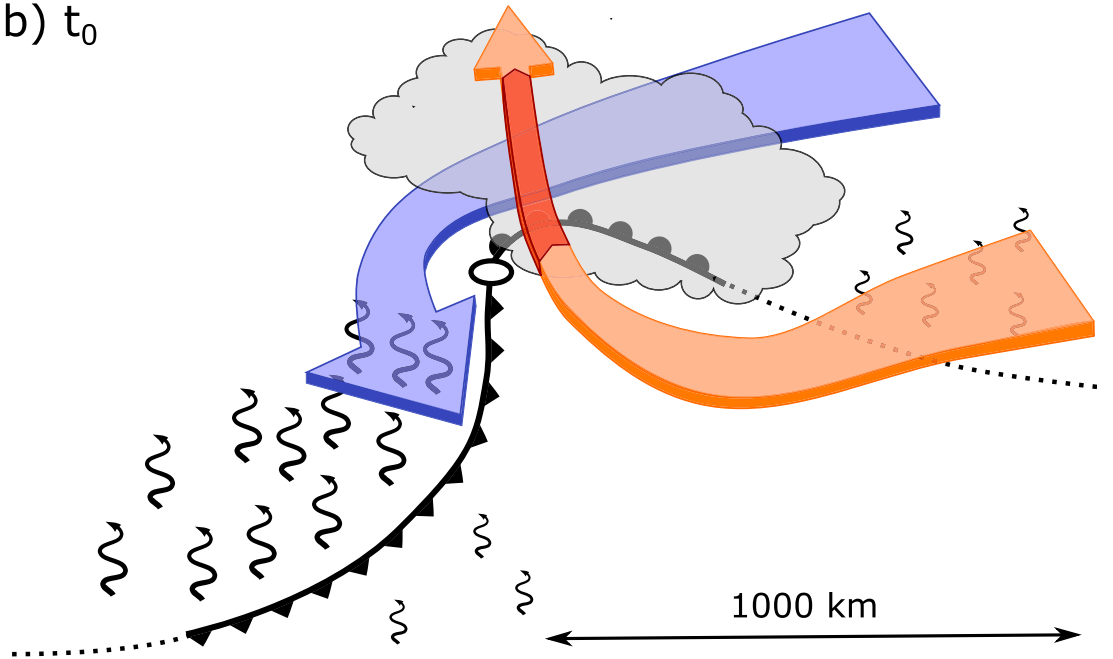

FIG. 11. Conceptual schematic of the cyclone-relative surface airstream (a) $24 \mathrm{~h}$ prior and (b) at the stage of the fastest deepening. The warm and moist airstream (orange) takes up moisture from far ahead of the cyclone (darker red section) and moves deeper into the warm sector before ascending in the warm conveyor belt. The dry and cold airstream moves around the cyclone to the north of its core and descends over the higher SST, resulting in strong latent heat fluxes. The latent heat flux (wavy arrows) in the cold sector, however, contributes negligibly to the deepening of the cyclone.

Due to the nature of our idealized approach, there are some caveats related to the highly idealized SST distribution, atmospheric initial condition, as well as our choice of turning off radiation and having a constant Coriolis parameter. However, our findings are consistent with previous case studies using more realistic settings (e.g., Giordani and Caniaux 2001; Booth et al. 2012; de Vries et al. 2019), which highlights that the intensification of cyclones is more strongly dependent on absolute SST compared to SST gradients. Our results also imply the potential for an increase in intensification and lifetime of cyclones in a warmer future climate with higher SST, though bearing in mind that our simulation assumes an established upper-level baroclinic zone, which might be altered in a climate with different underlying SST.

Acknowledgments. We thank Annick Terpstra for providing the initialization code and Clemens Spensberger for discussing the setup of the idealized jet. The work was supported by the Research Council of Norway funded project on Unifying Perspectives on Atmosphere-Ocean Interactions during Cyclone
Development (UNPACC; Project 262220). We acknowledge the computing resources provided by UNINETT Sigma2 AS through the Project NN9625K.

\section{APPENDIX}

\section{Basic-State Jet}

The zonally uniform jet stream takes the form

$$
u(y, z)=U_{0} W_{y}(y) W_{z}\left(z^{*}\right)
$$

where $y$ and $z$ are the meridional and vertical coordinates with the origin $(y=0, z=0)$ at the center of the jet core, where $y=0$ is also the center of the meridional domain, and $W_{y}$ and $W_{z}$ are the meridional and vertical weighting functions, respectively. The transformed vertical coordinate $z^{*}(y, z)$ accounts for changes in tropopause height,

$$
z^{*}(y, z)=z+A \tanh \left(\frac{y_{\text {jet }}-y}{B}\right),
$$


where $y_{\text {jet }}$ is the meridional location of the jet, which is located at the center of the domain $\left(y_{\text {jet }}=0\right) ; A$ and $B$ are the empirical parameters

$$
A(z)= \begin{cases}0 & \text { for } \quad z<-L_{z} \\ \left|Z_{\text {jet }}-Z_{\text {trop }}\right| \sin \left(\frac{\pi}{2} \frac{L_{z}+z}{L_{z}}\right) & \text { for } \quad-L_{z} \leq z \leq 0 \\ 1 & \text { for } \quad z>0\end{cases}
$$

$$
B=\frac{2 L_{y}}{5}
$$

with $Z_{\text {trop }}$ being tropopause height on the equatorward side of the jet $\left(y=-L_{y}\right), Z_{\text {jet }}$ is height of the jet stream core, and $L_{z}$ is the vertical extent of the jet from its core.

The meridional weighting function takes the form

$$
W_{y}(y)=\cos ^{2}\left(\frac{\pi}{2} \frac{y-y_{\text {jet }}}{L_{y}}\right),
$$

and the vertical weight spline function $W_{z}$ ensures constant vertical shear,

$W_{z}(z)= \begin{cases}1\left(\frac{z}{l_{1}}\right)^{2}\left[\frac{1}{6}\left(\frac{z}{l_{1}}\right)^{2}-1\right] & \text { for }|z| \leq l_{1} \\ w_{0}-\alpha|z| & \text { for } l_{1}<|z|<L_{z}-l_{2} \\ \frac{\alpha l_{2}}{2}\left(\frac{L_{z}-|z|}{l_{2}}\right)^{3}\left(2-\frac{L_{z}-|z|}{l_{2}}\right) & \text { for } \quad L_{z}-l_{2} \leq|z| \leq L_{z} \\ 0 & \text { for }|z|>L_{z},\end{cases}$

where $l_{1}$, and $l_{2}$ define the transition zones, both with a value of $0.04 L_{z}$. Other parameters are defined to ensure continuous functions and derivatives:

$$
\begin{aligned}
w_{0} & =\frac{1}{1-\frac{3}{8} \frac{l_{1}}{L_{z}-0.5 l_{2}}}, \\
C & =\frac{3}{4} w_{0} \frac{l_{1}}{L_{z}-0.5 l_{2}}, \\
a & =\frac{w_{0}}{L_{z}-0.5 l_{2}} .
\end{aligned}
$$

\section{REFERENCES}

Booth, J. F., L. Thompson, J. Patoux, and K. A. Kelly, 2012: Sensitivity of midlatitude storm intensification to perturbations in the sea surface temperature near the Gulf Stream. Mon. Wea. Rev., 140, 1241-1256, https://doi.org/10.1175/MWR-D-11-00195.1.

Boutle, I. A., R. J. Beare, S. E. Belcher, A. R. Brown, and R. S. Plant, 2010: The moist boundary layer under a mid-latitude weather system. Bound.-Layer Meteor., 134, 367-386, https:// doi.org/10.1007/s10546-009-9452-9.
Brayshaw, D. J., B. Hoskins, and M. Blackburn, 2008: The stormtrack response to idealized SST perturbations in an aquaplanet GCM. J. Atmos. Sci., 65, 2842-2860, https://doi.org/ 10.1175/2008JAS2657.1.

Chen, S.-H., and W.-Y. Sun, 2002: A one-dimensional time dependent cloud model. J. Meteor. Soc. Japan, 80, 99-118, https://doi.org/10.2151/jmsj.80.99.

Dacre, H. F., O. Martínez-Alvarado, and C. O. Mbengue, 2019: Linking atmospheric rivers and warm conveyor belt airflows. J. Hydrometeor., 20, 1183-1196, https://doi.org/10.1175/ JHM-D-18-0175.1.

de Vries, H., S. Scher, R. Haarsma, S. Drijfhout, and A. van Delden, 2019: How Gulf-Stream SST-fronts influence Atlantic winter storms. Climate Dyn., 52, 5899-5909, https://doi.org/ 10.1007/s00382-018-4486-7.

Dudhia, J., 1996: A multi-layer soil temperature model for MM5. Sixth Mesoscale Model Users' Workshop, Boulder, CO, PSU-NCAR, 49-50.

Giordani, H., and G. Caniaux, 2001: Sensitivity of cyclogenesis to sea surface temperature in the northwestern Atlantic. Mon. Wea. Rev., 129, 1273-1295, https://doi.org/10.1175/1520-0493(2001) 129<1273:SOCTSS $>2.0 . C O ; 2$.

Gyakum, J. R., J. R. Anderson, R. H. Grumm, and E. L. Gruner, 1989: North Pacific cold-season surface cyclone activity: 1975-1983. Mon. Wea. Rev., 117, 1141-1155, https://doi.org/ 10.1175/1520-0493(1989)117<1141:NPCSSC>2.0.CO;2.

Haualand, K. F., and T. Spengler, 2020: Direct and indirect effects of surface fluxes on moist baroclinic development in an idealized framework. J. Atmos. Sci., 77, 3211-3225, https:// doi.org/10.1175/JAS-D-19-0328.1.

Hirata, H., R. Kawamura, M. Kato, and T. Shinoda, 2015: Influential role of moisture supply from the Kuroshio/Kuroshio Extension in the rapid development of an extratropical cyclone. Mon. Wea. Rev., 143, 4126-4144, https://doi.org/10.1175/MWRD-15-0016.1.

Hong, S.-Y., Y. Noh, and J. Dudhia, 2006: A new vertical diffusion package with an explicit treatment of entrainment processes. Mon. Wea. Rev., 134, 2318-2341, https://doi.org/ 10.1175/MWR3199.1.

Hoskins, B. J., and P. J. Valdes, 1990: On the existence of stormtracks. J. Atmos. Sci., 47, 1854-1864, https://doi.org/10.1175/ 1520-0469(1990)047<1854:OTEOST>2.0.CO;2.

Jacobs, N. A., S. Raman, G. M. Lackmann, and P. P. Childs, 2008: The influence of the Gulf Stream induced SST gradients on the US East Coast winter storm of 24-25 January 2000. Int. J. Remote Sens., 29, 6145-6174, https://doi.org/ 10.1080/01431160802175561.

Jiménez, P. A., J. Dudhia, J. F. González-Rouco, J. Navarro, J. P. Montávez, and E. García-Bustamante, 2012: A revised scheme for the WRF surface layer formulation. Mon. Wea. Rev., 140, 898-918, https://doi.org/10.1175/MWR-D-11-00056.1.

Kain, J. S., 2004: The Kain-Fritsch convective parameterization: An update. J. Appl. Meteor., 43, 170-181, https://doi.org/ 10.1175/1520-0450(2004)043<0170:TKCPAU>2.0.CO;2.

Kuo, Y.-H., S. Low-Nam, and R. J. Reed, 1991: Effects of surface energy fluxes during the early development and rapid intensification stages of seven explosive cyclones in the western Atlantic. Mon. Wea. Rev., 119, 457-476, https://doi.org/ 10.1175/1520-0493(1991)119<0457:EOSEFD>2.0.CO;2.

Kuwano-Yoshida, A., and S. Minobe, 2017: Storm-track response to SST fronts in the northwestern Pacific region in an AGCM. J. Climate, 30, 1081-1102, https://doi.org/10.1175/ JCLI-D-16-0331.1. 
Lorenz, E. N., 1955: Available potential energy and the maintenance of the general circulation. Tellus, 7, 157-167, https:// doi.org/10.3402/tellusa.v7i2.8796.

Madonna, E., H. Wernli, H. Joos, and O. Martius, 2014: Warm conveyor belts in the ERA-Interim dataset (1979-2010). Part I: Climatology and potential vorticity evolution. J. Climate, 27, 3-26, https://doi.org/10.1175/JCLI-D-12-00720.1.

Mansfield, D. A., 1974: Polar lows: The development of baroclinic disturbances in cold air outbreaks. Quart. J. Roy. Meteor. Soc., 100, 541-554, https://doi.org/10.1002/qj.49710042604.

Nakamura, H., T. Sampe, Y. Tanimoto, and A. Shimpo, 2004: Observed associations among storm tracks, jet streams and midlatitude oceanic fronts. Earth's Climate: The OceanAtmosphere Interaction, Geophys. Monogr., Vol. 147, Amer. Geophys. Union, 329-346.

$\longrightarrow,-$ A. Goto, W. Ohfuchi, and S.-P. Xie, 2008: On the importance of midlatitude oceanic frontal zones for the mean state and dominant variability in the tropospheric circulation. Geophys. Res. Lett., 35, L15709, https://doi.org/ 10.1029/2008GL034010.

Ogawa, F., and T. Spengler, 2019: Prevailing surface wind direction during air-sea heat exchange. J. Climate, 32, 5601-5617, https://doi.org/10.1175/JCLI-D-18-0752.1.

Papritz, L., and T. Spengler, 2015: Analysis of the slope of isentropic surfaces and its tendencies over the North Atlantic. Quart. J. Roy. Meteor. Soc., 141, 3226-3238, https://doi.org/10.1002/qj.2605.

Reed, R. J., G. A. Grell, and Y.-H. Kuo, 1993: The ERICA IOP 5 storm. Part II: Sensitivity tests and further diagnosis based on model output. Mon. Wea. Rev., 121, 1595-1612, https://doi.org/ 10.1175/1520-0493(1993)121<1595:TEISPI>2.0.CO;2.

Sanders, F., and J. R. Gyakum, 1980: Synoptic-dynamic climatology of the "bomb." Mon. Wea. Rev., 108, 1589-1606, https://doi.org/ 10.1175/1520-0493(1980)108<1589:SDCOT $>2.0 . C O ; 2$.

Schemm, S., H. Wernli, and L. Papritz, 2013: Warm conveyor belts in idealized moist baroclinic wave simulations. J. Atmos. Sci., 70, 627-652, https://doi.org/10.1175/JAS-D-12-0147.1.

Sheldon, L., A. Czaja, B. Vannière, C. Morcrette, B. Sohet, M. Casado, and D. Smith, 2017: A 'warm path' for Gulf Streamtroposphere interactions. Tellus, 69A, 1299397, https://doi.org/ 10.1080/16000870.2017.1299397.

Skamarock, W. C., and Coauthors, 2008: A description of the Advanced Research WRF version 3. NCAR Tech. Note NCAR/TN475+STR, 113 pp., https://doi.org/10.5065/D68S4MVH.

Small, R. J., R. A. Tomas, and F. O. Bryan, 2014: Storm track response to ocean fronts in a global high-resolution climate model. Climate Dyn., 43, 805-828, https://doi.org/10.1007/s00382-013-1980-9.
—- R. Msadek, Y.-O. Kwon, J. F. Booth, and C. Zarzycki, 2019: Atmosphere surface storm track response to resolved ocean mesoscale in two sets of global climate model experiments. Climate Dyn., 52, 2067-2089, https://doi.org/ 10.1007/s00382-018-4237-9.

Sprenger, M., E. Zurich, and H. Wernli, 2015: The LAGRANTO Lagrangian analysis tool-Version 2.0. Geosci. Model Dev., 8, 2569-2586, https://doi.org/10.5194/gmd-8-2569-2015.

Taguchi, B., H. Nakamura, M. Nonaka, and S.-P. Xie, 2009: Influences of the Kuroshio/Oyashio Extensions on air-sea heat exchanges and storm-track activity as revealed in regional atmospheric model simulations for the 2003/04 cold season. J. Climate, 22, 6536-6560, https://doi.org/10.1175/ 2009JCLI2910.1.

Terpstra, A., and T. Spengler, 2015: An initialization method for idealized channel simulations. Mon. Wea. Rev., 143, 2043-2051, https://doi.org/10.1175/MWR-D-14-00248.1.

,-- , and R. W. Moore, 2015: Idealised simulations of polar low development in an Arctic moist-baroclinic environment. Quart. J. Roy. Meteor. Soc., 141, 1987-1996, https://doi.org/ 10.1002/qj.2507.

Tierney, G., D. J. Posselt, and J. F. Booth, 2018: An examination of extratropical cyclone response to changes in baroclinicity and temperature in an idealized environment. Climate Dyn., 51, 3829-3846, https://doi.org/10.1007/s00382-018-4115-5.

Tsopouridis, L., T. Spengler, and C. Spensberger, 2020: SST fronts along the Gulf Stream and Kuroshio affect the winter climatology primarily in the absence of cyclones. Wea. Climate Dyn. Discuss., https://doi.org/10.5194/wcd-2020-50.

- C. Spensberger, and T. Spengler, 2021a: Characteristics of cyclones following different pathways in the Gulf Stream region. Quart. J. Roy. Meteor. Soc., 147, 392-407, https://doi.org/ 10.1002/qj.3924.

,-- , and - 2021b: Cyclone intensification in the Kuroshio region and its relation to the sea surface temperature front and upper-level forcing. Quart. J. Roy. Meteor. Soc., 147, 485-500, https://doi.org/10.1002/qj.3929.

Yanase, W., and H. Niino, 2019: Parameter sweep experiments on a spectrum of cyclones with diabatic and baroclinic processes. J. Atmos. Sci., 76, 1917-1935, https://doi.org/ 10.1175/JAS-D-18-0232.1.

Yoshiike, S., and R. Kawamura, 2009: Influence of wintertime large-scale circulation on the explosively developing cyclones over the western North Pacific and their downstream effects. J. Geophys. Res., 114, D13110, https://doi.org/10.1029/ 2009JD011820. 